\title{
Patterns of Diurnal Marine Stratocumulus Cloud Fraction Variability*
}

\author{
CASEY D. BURLEYSON \\ North Carolina State University, Raleigh, North Carolina, and Pacific Northwest National Laboratory, \\ Richland, Washington
}

SANDRA E. YUTER

North Carolina State University, Raleigh, North Carolina

(Manuscript received 14 July 2014, in final form 15 January 2015)

\begin{abstract}
The spatial patterns of subtropical marine stratocumulus cloud fraction variability on diurnal time scales are examined using high-temporal-resolution cloud masks that are based on 30-min, $4 \mathrm{~km} \times 4 \mathrm{~km}$ geosynchronous infrared data for 2003-10. This dataset permits comparison of the characteristics of variability in low cloud fraction among the three subtropical marine stratocumulus regions in the northeastern (NE) Pacific, southeastern (SE) Pacific, and SE Atlantic Oceans. In all three regions, the largest diurnal cycles and earliest time of cloud breakup occur on the edges of the cloud field where cloud fractions are generally lower. The rate at which the cloud breaks up during the day is tied to the starting cloud fraction at dawn, which determines the amount of longwave cooling that is initially available to offset shortwave radiative fluxes during the day. The maximum rate of cloud breakup occurs near 1200 LT. Cloud fraction begins to increase by 1600 LT (before the sun sets) and reaches its maximum value just before dawn. The diurnal-cycle characteristics of the SE Pacific and SE Atlantic marine stratocumulus cloud decks are more similar to each other than to those in the NE Pacific. The NE Pacific cloud deck has a smaller-amplitude diurnal cycle, slower rates of cloud breakup during the day for a given cloud fraction at dawn, and a higher probability of cloud breakup overnight.
\end{abstract}

\section{Introduction}

The temporal and spatial variability of subtropical marine stratocumulus cloud fraction is in large part driven by diurnal variations in the strength and depth of turbulent mixing, which in turn are forced by changes in radiative flux divergence at cloud top (James 1959; Lilly 1968; Nicholls 1984; Betts 1990; Turton and Nicholls 1987; Duynkerke 1989; Caldwell et al. 2005; Burleyson et al. 2013). Studies of the joint interactions among cloud fraction, turbulent mixing, and radiative flux divergence have been hampered by the lack of high-temporal/spatial-resolution satellite cloud products. Several of the processes

\footnotetext{
* Supplemental information related to this paper is available at the Journals Online website: http://dx.doi.org/10.1175/JAMC-D14-0178.s1.

Corresponding author address: Dr. Casey D. Burleyson, Pacific Northwest National Laboratory, P.O. Box 999/MS K9-24, Richland, WA 99352.

E-mail: casey.burleyson@pnnl.gov.
}

hypothesized to be important in modulating stratocumulus can vary across time scales of a few hours (e.g., Allen et al. 2013; Burleyson et al. 2013; Wilbanks et al. 2014, manuscript submitted to Mon. Wea. Rev.). Observational datasets with subhourly update times are thus critical to resolving the complete temporal range of cloudiness variability.

The International Satellite Cloud Climatology Project (ISCCP; Rossow and Schiffer 1991) and the Climatic Atlas of Clouds Over Land and Ocean (Hahn and Warren 2007) provide useful avenues for exploring subtropical marine stratocumulus cloudiness variability on multiday-or-longer time scales. ISCCP data provide information on average cloud fractions over several hundred kilometers on time scales as small as $3 \mathrm{~h}$ and as large as seasonal means. The Climatic Atlas of Clouds Over Land and Ocean database provides mean cloud fraction over areas on the scale of $5^{\circ} \times 5^{\circ}$. These data products are widely used and can effectively capture gross features of the seasonal and diurnal cycles of subtropical marine stratocumulus clouds as well as long-term trends in cloudiness. The four-times-daily cloud fraction 
estimates from the sun-synchronous Moderate Resolution Imaging Spectroradiometer (MODIS; Platnick et al. 2003) sensors aboard the National Aeronautics and Space Administration (NASA) Aqua and Terra satellites have high spatial resolution but can only crudely address rates of change of cloudiness at subdiurnal time scales.

Subtropical marine stratocumulus clouds are relatively simple in comparison with multilayered cloud fields in the tropics and midlatitudes. For the most part, stratocumulus cloud-top temperatures and the underlying sea surface temperatures (SSTs) have gradual spatial and temporal variations (Zuidema et al. 2009; de Szoeke et al. 2012). In addition, large portions of the subtropical marine stratocumulus regions experience partial cloud breakup during the day. These combined properties often create a bimodal distribution of infrared (IR) brightness temperatures (hereinafter $\mathrm{Tb}$ ) corresponding to clear-sky (ocean) and cloudy pixels. We use an adaptive empirical monospectral threshold method applied to $11.5-\mu \mathrm{m}$ IR Tb measurements to determine cloud fraction on the basis of geosynchronous IR data with a pixel resolution of $4 \mathrm{~km} \times 4 \mathrm{~km}$. For the purposes of this paper, we define cloud as optically thick cloud on spatial scales of greater than or equal to $4 \mathrm{~km} \times$ $4 \mathrm{~km}$. The unique aspect of this analysis is the application of this technique to a 30-min-temporal-resolution IR $\mathrm{Tb}$ dataset. The cloud masks derived from this dataset allow us to perform a detailed analysis of cloud fraction variability at 30-min increments across the diurnal cycle and to replicate the analysis in each of the three main subtropical marine stratocumulus decks in the northeastern (NE) Pacific, southeastern (SE) Pacific, and SE Atlantic Oceans.

Section 2 describes the parameters of the IR Tb dataset. In section 3 , we outline our method for converting the IR Tb measurements into cloud masks. We discuss multiple ways in which we evaluate the fidelity of the new product by qualitatively and quantitatively comparing the IR-based cloud masks with other datasets on a variety of spatial and temporal scales. We document the patterns associated with the diurnal cycle of cloud fraction in each of the subtropical marine stratocumulus regions in section 4 . We show that the diurnal cycle within each region and season unfolds in a regular manner and that the rate of cloud breakup during the day is strongly dependent on both shortwave (SW) radiative fluxes and local cloud fraction at dawn. We close in section 5 by summarizing our findings.

\section{Data}

Our primary dataset is version 1 of the 30-mintemporal-resolution, 4-km Global IR Dataset, a NASA
Tropical Rainfall Measuring Mission ancillary dataset from the Climate Prediction Center, National Centers for Environmental Prediction, and National Weather Service (Janowiak et al. 2001; see online at http://www.cpc.ncep. noaa.gov/products/global_precip/html/README). This global IR product (hereinafter merged-IR) combines data from multiple geostationary satellites [Geostationary Operational Environmental Satellites (GOES), Meteosat satellites, and Geostationary Meteorological Satellites] into a spatially complete field of IR Tb from $60^{\circ} \mathrm{S}$ to $60^{\circ} \mathrm{N}$. GOES-East and GOES-West (4-km nadir IR resolution) provide coverage of the stratocumulus regions in the $\mathrm{Pa}$ cific, while Meteosat-7 (3-km nadir IR resolution) was the primary satellite covering the SE Atlantic basin (Janowiak et al. 2001, their Fig. 1). The merged-IR product maps all satellite pixels to a common $4 \mathrm{~km} \times 4 \mathrm{~km}$ grid (Janowiak et al. 2001). We use merged-IR data from 2003 to 2010 in this analysis.

Intercalibration among satellites was not performed in the version of the merged-IR product we used (version 1). The calibration offsets are likely an order of magnitude smaller than the viewing-angle-dependence effect (Joyce and Arkin 1997). In addition, our adaptive method, described below, utilizes the shape of the IR Tb distribution for each region and is therefore less sensitive to calibration errors than is an approach that uses absolute thresholds.

The merged-IR product includes an empirical zenithangle correction to provide a consistent measurement across the full field of view (Wark et al. 1962; Joyce and Arkin 1997; Janowiak et al. 2001). The zenith-angle correction also reduces the spatial discontinuities at the boundaries between the fields of view of neighboring satellites. There are a few geographic locations at which the zenith-angle correction appears to have been applied incorrectly, however, yielding nonphysical arcs in the IR Tb field. An example of these nonphysical arcs in the NE Pacific is shown within the teal box in Fig. 1. There is degraded data quality in areas where the zenithangle correction is apparently not performing well, which leads to uncorrectable errors in our cloud-identification algorithm and an erroneous estimation of cloud fraction. The area in the NE Pacific is the only obvious example of consistently poor data quality that is within or directly adjacent to the stratocumulus cloud deck in any of the three subtropical marine stratocumulus regions that we examined. Data from this area are removed from our analysis (sections 3 and 4). In addition, there are data artifacts in the form of subtle vertical striping outside of our quantitative-analysis regions in the SE Pacific and SE Atlantic (section 4).

As part of the evaluation of our cloud-identification algorithm, we use level-2 MODIS "MOD06_L2" (Terra 


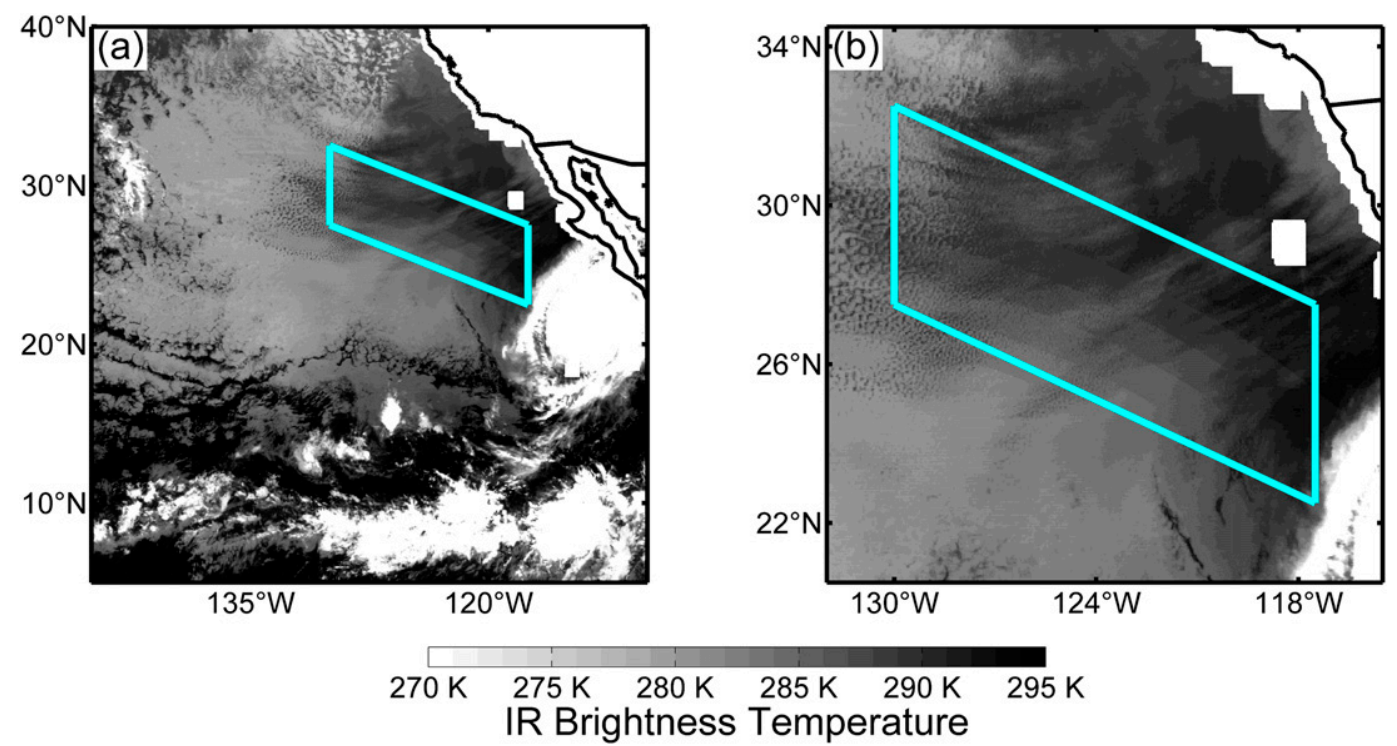

FIG. 1. (a) IR Tb observed off the coast of California at 1400 UTC 10 Oct 2008, and (b) the area in the blue polygon in (a) where an example of the zenith-angle-correction error can be seen in the arcs of lower Tb.

satellite) and "MYD06_12" (Aqua satellite) cloud products from Collection 5 (King et al. 2003; Platnick et al. 2003), including the MODIS Cloud_Fraction field (http:// modis-atmos.gsfc.nasa.gov/MOD06_L2/format.html). The MODIS Cloud_Fraction provides fractional cloudiness at $5 \mathrm{~km} \times 5 \mathrm{~km}$ spatial resolution. The MODIS instrument measures several visible-band radiances at 250- and 500-m nadir spatial resolution and other visible radiances and IR $\mathrm{Tb}$ at $1-\mathrm{km}$ nadir spatial resolution (Ackerman et al. 1998). Hence, the MODIS 1-km cloud mask, which is used to compute MODIS cloud fraction at $5 \mathrm{~km} \times 5 \mathrm{~km}$, is based in part on information at $250-\mathrm{m}$ nadir spatial resolution during the day and is limited to information at 1-km nadir spatial resolution at night (Frey et al. 2008). Combining data from the Aqua and Terra sunsynchronous satellites yields four MODIS overpasses per day at approximately 0130, 1030,1330, and 2230 LT (King et al. 2003; Platnick et al. 2003). We use MODIS data from September 2002 through August 2011. In addition, we also compare examples of our cloud mask at $4 \mathrm{~km} \times 4 \mathrm{~km}$ resolution with GOES visible data at $1 \mathrm{~km} \times 1 \mathrm{~km}$ resolution in the SE Pacific. SST measurements are from the Remote Sensing Systems' optimally interpolated daily SST product (Reynolds and Smith 1994).

\section{IR-based cloud-identification method}

ISCCP was the first to produce an operational global cloud product from multiple satellites (Rossow and Schiffer 1991). ISCCP used both visible and IR data during the day and IR data at night. We use only IR data in this analysis because they provide a consistent measurement across the diurnal cycle. Use of IR data at night and a combination of IR and visible data during the day will yield a product that is more sensitive to thin clouds during the day (Holz et al. 2008; R. Frey 2014, personal communication) and hence is not uniform across the diurnal cycle. Because our focus is on the relative diurnal variability of stratocumulus clouds, it is important to have a consistent measurement at all times of day. Whereas the ISCCP IR threshold method uses IR data degraded to 30-km spatial resolution, we use 4-km spatial resolution. Unlike ISCCP, we do not utilize a radiative transfer calculation to determine clear-sky IR Tb. Rather, we exploit the simplicity of the low-cloud and ocean field in subtropical marine stratocumulus regions and use the shape characteristics of the IR Tb frequency distribution to determine the threshold temperature for cloud identification. Our algorithm is designed to work only in subtropical marine stratocumulus regions.

\section{a. Description of cloud-identification method}

Cloud-top temperatures and SSTs in the subtropical stratocumulus regions each vary slowly in both space and time (Zuidema et al. 2009; de Szoeke et al. 2012). In these regions, the accumulated frequency distributions of IR Tb over several weeks or over a large area often have a bimodal structure, with the two modes corresponding to low cloud and ocean (Fig. 2a). The bimodal structure associated with ocean and cloud emissions was noted by Saunders and Kriebel (1988, their Fig. 1). When cloud fractions remain either high or low, IR Tb distributions are unimodal such that only the lower or higher temperature cloud or ocean mode is present 
Bimodal Distribution

(a) $\left[21^{\circ} \mathrm{S}-18^{\circ} \mathrm{S}\right] \quad\left[94^{\circ} \mathrm{W}-91^{\circ} \mathrm{W}\right] \quad 16-$ Nov $2008+/-2$ Weeks

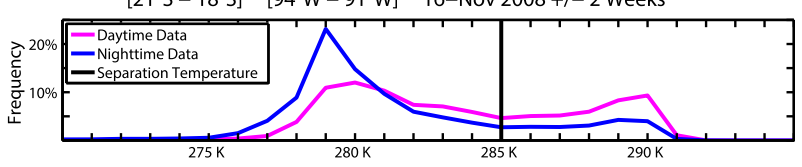

(b) Unimodal Distribution

(b) $\left[21^{\circ} \mathrm{S}-18^{\circ} \mathrm{S}\right] \quad\left[76^{\circ} \mathrm{W}-73^{\circ} \mathrm{W}\right] \quad 16-$ Nov $2008+/-2$ Weeks

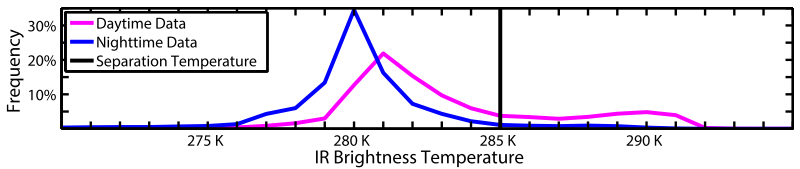

FIG. 2. Two examples of the accumulated Tb distributions in $3^{\circ} \times$ $3^{\circ}$ boxes over the SE Pacific. (a) An example of a region well offshore where the cloud fractions are lower and the distributions of daytime temperatures (magenta lines) are more bimodal. (b) In contrast, these distributions come from an area closer to the coast where cloud fractions remain high even during the day, resulting in a mostly unimodal distribution of Tb. The black line in each panel indicates the likely separation temperature between the cloudy and cloud-free modes.

(Fig. 2b). In this study, the IR Tb distributions are accumulated over a moving 4-week window centered on a given day. The distributions are spatially aggregated in each $3^{\circ} \times 3^{\circ}$ box (approximately 6800 pixels, with pixels at $4 \mathrm{~km} \times 4 \mathrm{~km}$ resolution) that covers the subtropical marine stratocumulus regions (thin black boxes in Fig. 3). Our method finds the temperature in the daytime IR Tb distribution that most likely separates the cloud and ocean portions of the distribution and uses that value as the threshold temperature for both day and night. The daytime distributions are used because cloud fraction is usually minimized during the day (Turton and Nicholls 1987; Betts 1990; de Szoeke et al. 2012), creating a more evident SST mode. Implicit in the use of daytime scenes to identify a separation temperature (ST) for the entire day is the assumption that SSTs do not vary significantly (more than $1-2 \mathrm{~K}$ ) across the diurnal cycle (de Szoeke et al. 2010; Painemal et al. 2010).
The derivative of the curve defined by the daytime IR $\mathrm{Tb}$ frequency distribution is used to find the candidate separation temperature. In the case of strongly bimodal distributions, the candidate ST is where the derivative goes to zero, that is, the local minimum between the two modes (Fig. 2a). The underlying premise is that the minimum frequency between the two modes corresponds to the temperature that is least likely to be in either the cloudy or cloud-free mode and thus is most likely to separate the two. The daytime IR Tb distributions within our $3^{\circ} \times 3^{\circ}$ boxes are strongly bimodal $68 \%$ of the time in the NE Pacific, $80 \%$ of the time in the SE Pacific, and $72 \%$ of the time in the SE Atlantic.

For unimodal or weakly bimodal daytime IR Tb distributions, the candidate separation temperature is defined where the derivative is closest to zero and either warmer than the lower temperature mode in high cloud fraction regions or colder than the higher temperature mode in low cloud fraction regions. This candidate ST is chosen in an attempt to objectively isolate the single mode that is present. Our algorithm requires that the identified mode have an amplitude of greater than $10 \%$. When this condition is not met, or if the candidate ST is more than $15 \mathrm{~K}$ from the temperature at the peak of the single mode, the method returns a missing value (about $5 \%-10 \%$ of the time).

In the next step, the time series of daily candidate separation temperatures for a given box is filtered to remove outliers (data points in which the ST for a single day differs from the running 2 -week mean value by more than $2 \mathrm{~K}$ ) and is then interpolated in time to fill in gaps for which a candidate ST was not found (Fig. 4). The interpolated time series for each $3^{\circ} \times 3^{\circ}$ box is then used to create an ST map for every day. We use spatial interpolation among boxes to reduce horizontal discontinuities in the ST for adjacent boxes. This procedure yields a final ST map that is smoothly varying in both space and time. The resulting maps of the ST have
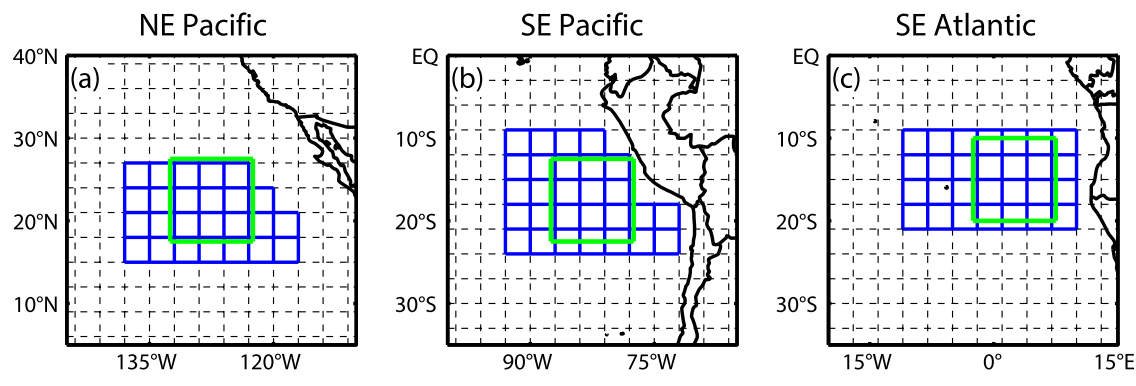

FIG. 3. Black dashed lines outline the $3^{\circ} \times 3^{\circ}$ boxes where the distributions of IR Tb were aggregated to create the merged-IR cloud masks. Blue boxes indicate the areas where low cloud fraction was calculated in the quantitative sections of our analysis, and the green box in each region is the $10^{\circ} \times 10^{\circ}$ region where areal cloud fractions were calculated for Figs. 19 and 20, described below. Boxes are shown for the (a) NE Pacific, (b) SE Pacific, and (c) SE Atlantic. 


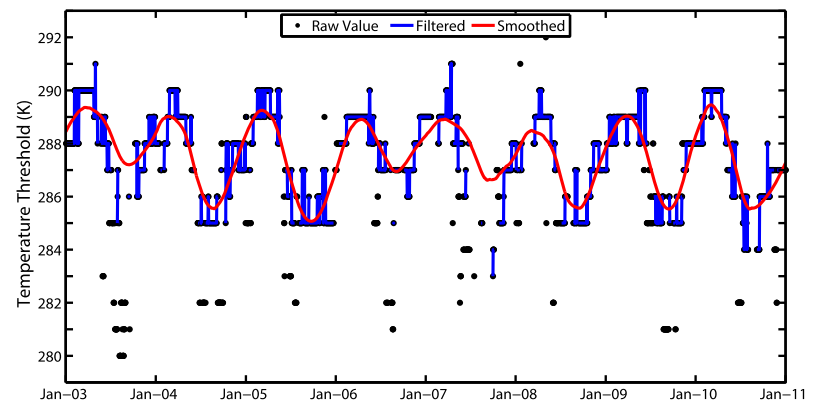

FIG. 4. Time series from 2003 to 2010 of the candidate ST values calculated for an example $3^{\circ} \times 3^{\circ}$ box $\left(20^{\circ}-17^{\circ} \mathrm{S}, 76^{\circ}-73^{\circ} \mathrm{W}\right)$ in the SE Pacific (black dots), and the filtered (blue line) and smoothed (red line) versions of the same time series. Note that there are many periods during which the blue line obscures the black dots underneath.

a spatial structure that is similar to that of SST maps for each day, and the time series of ST (e.g., Fig. 4) has a seasonal phase and amplitude that are similar to those the SST seasonal cycle (not shown). Once we have an ST map for every day, we can create a cloud mask at $4 \mathrm{~km} \times$ $4 \mathrm{~km}$ spatial resolution for all 30-min scenes during each day by identifying pixels with an IR Tb that is colder (cloud) and warmer (ocean) than the ST.

An example cloud mask is shown in Fig. 5 relative to a GOES visible albedo image from the SE Pacific at 1600 UTC 11 October 2008. From a regional perspective (Figs. 5a,c,e), our product captures the broad-scale features of the stratocumulus cloud deck, including the east-west decrease in cloudiness and the reduction in cloud fraction along the Peruvian coastline. We can compare finer-scale details of the cloud deck in an $8.5^{\circ} \times$ $8.5^{\circ}$ region (Figs. $5 \mathrm{~b}, \mathrm{~d}, \mathrm{f}$ ). Our method picks up on the high cloud fraction characteristics of the closed-cellular regions in the southeast and northeast corners of the region as well as many of the intricate cloud edges within the open-cellular region in the center of the frame. Our cloud mask does not capture some of the very finescale features like the slight reduction in cloudiness between adjacent cells in the closed-cell regions. Detailed examination of the IR Tb maps (Figs. 5a,b) and the GOES visible albedo maps (Figs. 5e,f) suggests that these subtle differences are not an erroneous identification of clouds; they are instead the result of discrepancies in the native resolution of the merged-IR data $(4 \mathrm{~km} \times 4 \mathrm{~km})$ and the GOES visible albedo data $(1 \mathrm{~km} \times 1 \mathrm{~km})$. Additional examples of cloud mask and GOES comparisons are included in the online supplemental material.

The separation-temperature method described above distinguishes clouds from ocean and yields a total cloud mask. We evaluate the total cloud mask obtained using our method against MODIS total cloud fractions in section $3 b$. Mixed-phase and ice clouds are occasionally
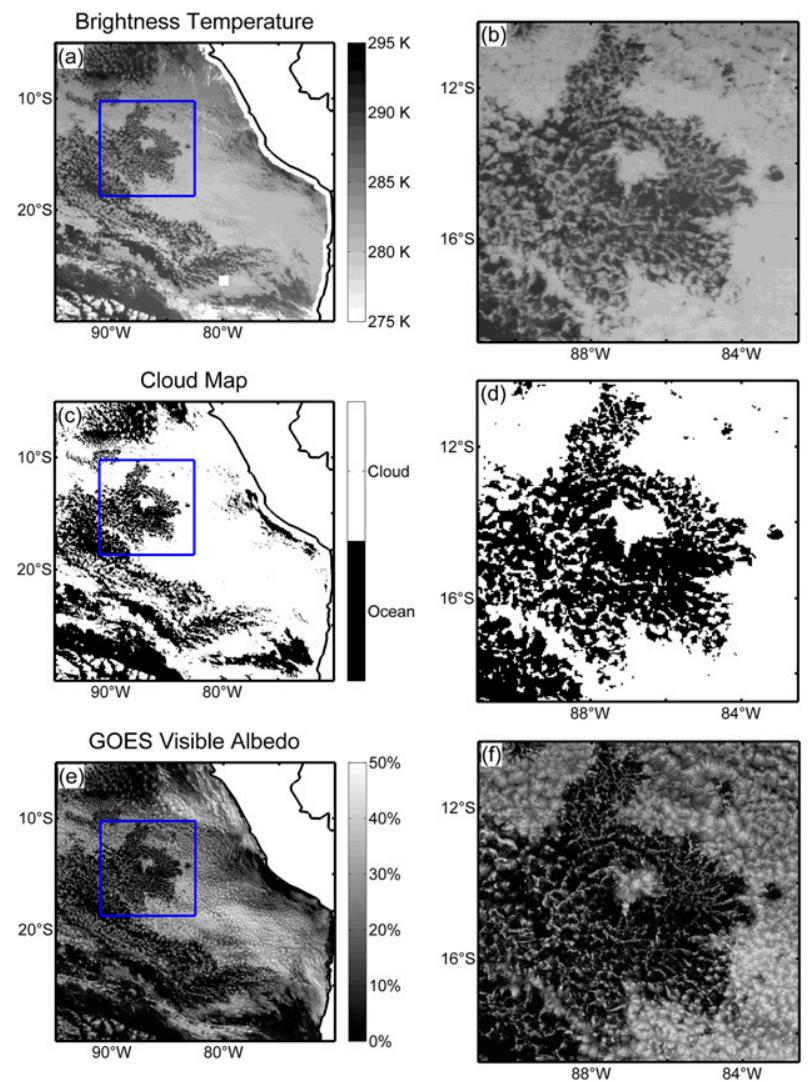

FIG. 5. (a),(b) The Tb from the merged-IR dataset over the SE Pacific at 1600 UTC 11 Oct 2008. (c),(d) The corresponding cloud mask generated using the cloud-identification method. The mergedIR cloud mask can be compared with (e),(f) the GOES visible albedo data. (right) The $8.5^{\circ} \times 8.5^{\circ}$ region that is (left) outlined in blue.

present above the liquid-phase marine stratocumulus (e.g., Wood et al. 2011b, their Figs. 2-4). Again, the simplicity of the cloudiness conditions allows us to use a simple threshold to distinguish low liquid-phase stratocumulus clouds from mixed-phase and ice clouds. Clouds with IR $\mathrm{Tb}<270 \mathrm{~K}$ are identified as containing ice. Clouds containing both ice and liquid hydrometeors are rarely present in subtropical marine stratocumulus regions because the strong boundary layer inversion limits upward growth of the cloud top (de Szoeke et al. 2012; Burleyson et al. 2013). Information on the annual occurrence of mixed-phase and ice clouds is used to determine an empirical geographic boundary for the subtropical marine stratocumulus regions that are the focus of this study. We define our regions of interest as having ice-containing clouds less than $35 \%$ of the year. A threshold of $35 \%$ effectively isolates the stratocumulus cloud deck from the ITCZ to the south in the NE Pacific and the midlatitude storm track in all three regions (Fig. S1 in the supplemental material). We mask out regions where MODIS cloud-top temperatures 
below freezing occur more than $35 \%$ of the time and where the "smudging" in the merged-IR product described in section 2 occurs (e.g., Figs. 11 and 12, described in detail below). The sets of $3^{\circ} \times 3^{\circ}$ boxes used in our quantitative analysis for each region (blue boxes in Fig. 3) fit within these empirically determined regions.

In addition, we want to separate low clouds from all clouds and need to address the occasional patch of mixed-phase or ice clouds. To calculate low cloud fraction within an individual $3^{\circ} \times 3^{\circ}$ box, we use the number of $4 \mathrm{~km} \times 4 \mathrm{~km}$ cloudy pixels (determined from the ST method described above) with IR $\mathrm{Tb}>270 \mathrm{~K}$ and divide that by the number of pixels in the box minus any pixels with IR $\mathrm{Tb} \leq 270 \mathrm{~K}$. In effect, when mixed-phase or ice clouds are present, the area of an individual $3^{\circ} \times 3^{\circ}$ box at a given time is reduced for the purpose of the low cloud fraction calculation. When calculating the cloud fraction time series in the $3^{\circ} \times 3^{\circ}$ or $10^{\circ} \times 10^{\circ}$ boxes, if more than $30 \%$ of the box was covered by mixed-phase or ice clouds for a given 30-min scene, then the whole box was counted as missing data and was dropped from the time series.

\section{b. Evaluation of the cloud-identification method}

The measurement of cloud fraction is highly sensitive to the instrument field of view (sensor pixel size at Earth's surface) and the minimum sensitivity of the instrument (Wielicki and Parker 1992; Di Girolamo and Davies 1997; King et al. 2003; Jones et al. 2012). Cloud edges are observed to have fractal characteristics (Lovejoy and Schertzer 1990). Hence, as the field of view increases, individual pixels are more likely to be partially filled with cloud. Typical meteorological-satellite observations have native sensor resolutions that are between $250 \mathrm{~m}$ and $8 \mathrm{~km}$. Algorithms to determine cloud fraction from satellite data use various assumptions to make choices about how to account for partially cloud-filled pixels (e.g., Minnis and Harrison 1984; Rossow et al. 1985; Ackerman et al. 1998; Platnick et al. 2003; Yang and Di Girolamo 2008; Pincus et al. 2012).

For a quantitative evaluation, we can compare our binary total cloud mask at $4 \mathrm{~km} \times 4 \mathrm{~km}$ spatial resolution with the fractional MODIS total cloud product at $5 \mathrm{~km} \times 5 \mathrm{~km}$ spatial resolution. We undertake our comparisons of areal and temporal cloud fraction with an expectation of larger differences between MODIS and merged-IR products during the day than during the night because the MODIS daytime product incorporates visible-band information that is available at 250 -m nadir spatial resolution (Ackerman et al. 1998; Platnick et al. 2003). Comparisons between MODIS day and night cloud products and the Cloud-Aerosol Lidar with Orthogonal Polarization (CALIOP) cloud product over water show that MODIS detects about $2 \%$ less cloud at night than during the day between $60^{\circ} \mathrm{S}$ and $60^{\circ} \mathrm{N}(\mathrm{Holz}$ et al. 2008; R. Frey 2014, personal communication).

We first determine a transfer standard to convert the individual MODIS $5 \mathrm{~km} \times 5 \mathrm{~km}$ fractional cloudiness values to binary cloud or no-cloud values using an iterative error-minimization approach. We used a criterion of smallest root-mean-square error between closest seasonal mean cloud fraction pixels computed from MODIS and our merged-IR products for the period from 2003 to 2010. We found that an individual MODIS pixel must be filled with clouds that cover $87 \%$ of its area $\left(25 \mathrm{~km}^{2}\right)$ before our algorithm will likely identify the associated merged-IR pixel $\left(16 \mathrm{~km}^{2}\right)$ as being cloudy. The transfer standard was designed to minimize the mean total error for all pixels and scenes and may not produce the right conversion for an individual pixel or scene. Use of the transfer standard sets the mean difference between the MODIS and merged-IR cloud fractions to zero but does not affect the relative distribution of the differences. In the following comparisons, we simplify the MODIS cloud fraction product as containing cloud (value of 1) if the cloud fraction for a single pixel is greater than or equal to $87 \%$ and as not containing cloud (value of 0 ) if the single pixel cloud fraction is less than $87 \%$. The binary MODIS cloud classification is then aggregated in time and compared with a similar aggregation of merged-IR cloud masks. Throughout the text we will refer to the converted binary MODIS cloud product as the filtered MODIS cloud fraction.

An example of filtered MODIS cloud fractions in comparison with the 30-min merged-IR total cloud fractions for a 1 -week period within a $3^{\circ} \times 3^{\circ}$ box from each of the three regions is shown in Fig. 6. We examined all four MODIS overpasses (day and night) from the two satellites (Aqua and Terra); the orbit swaths usually only intersected a given $3^{\circ} \times 3^{\circ}$ box once per day for each satellite, however. The specific boxes and time periods selected are somewhat arbitrary-similar results are obtained for other times and areas. Our cloudidentification method yields an areal cloud fraction that is within $1 \%-2 \%$ of the filtered MODIS value at each overpass most of the time. In a handful of instances during this time frame, our product underestimates or overestimates areal cloud fraction by $10 \%-20 \%$. Three different example scenes from the time series in the NE Pacific are shown in Fig. 7. Included are examples for which the merged-IR product relative to the filtered MODIS product is $10 \%$ too low, a close match, and $10 \%$ too high. The overestimation in the right column of Fig. 7 appears to be due to misclassified cloud pixels within the broken cloudiness region in the middle-right portion of the blue box. In the underestimation example in the left column of Fig. 7, it appears that the filtered MODIS cloud 
(a)

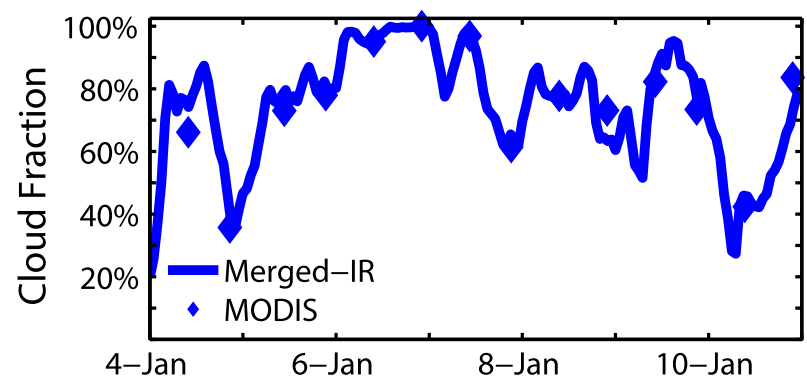

(b)

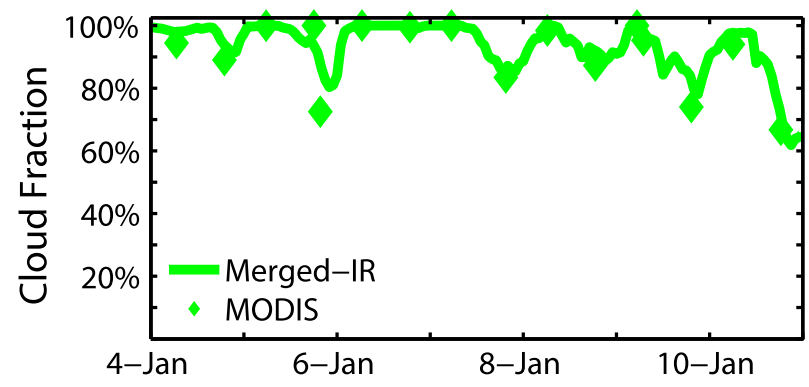

(c) SE Atlantic

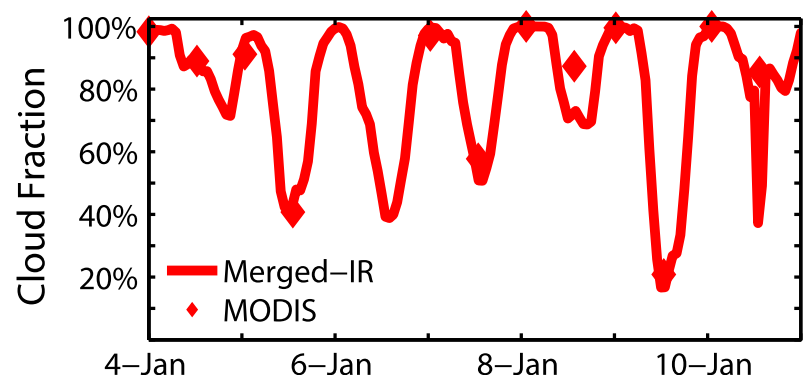

FIG. 6. Merged-IR (lines) and filtered MODIS (diamonds) total cloud fraction between 4 and 11 Jan 2004 for a single $3^{\circ} \times 3^{\circ}$ box in the (a) NE Pacific $\left(21^{\circ}-24^{\circ} \mathrm{N}, 129^{\circ}-126^{\circ} \mathrm{W}\right)$, (b) SE Pacific $\left(21^{\circ}-\right.$ $\left.18^{\circ} \mathrm{S}, 84^{\circ}-81^{\circ} \mathrm{W}\right)$, and (c) SE Atlantic $\left(15^{\circ}-12^{\circ} \mathrm{S}, 3^{\circ}-6^{\circ} \mathrm{E}\right)$.

mask identifies too much cloud in the center of the blue box. This could be due to a failure of the $87 \%$ transfer standard when applied to coarser-resolution pixels along the outer edges of the MODIS swath (Maddux et al. 2010). Because the position of the cloud measurement within each swath through the domain is effectively random on the time scales that we examine, we do not make an effort to account for the differences between coarser- and finerresolution pixels in the multiyear MODIS dataset.

We examine the distributions of differences in areal cloud fraction between the filtered MODIS product and the merged-IR product over the period 2003-10 for three $3^{\circ} \times 3^{\circ}$ boxes from each of the stratocumulus regions in Fig. 8. The boxes for each region span from east to west along the latitude of highest regional cloud fraction and were chosen to probe for spatial bias in the cloud identification from the merged-IR data. About 5000 MODIS scenes were examined for each region. The differences were calculated for each individual overpass and then aggregated. Each of the difference probability distributions has a large mode centered at $0 \%$, as expected from how the transfer standard was computed. The merged-IR areal cloud fractions are within $\pm 10 \%$ of the filtered MODIS areal cloud fraction $65 \%$ of the time in the NE Pacific, $80 \%$ of the time in the SE Pacific, and $70 \%$ of the time in the SE Atlantic. As a reference point for comparison, the two MODIS-based cloud products generated by the MODIS Science Team and the MODIS Clouds and the Earth's Radiant Energy System (CERES) Science Team differ in their estimated globally averaged low-cloud amounts by a full 10\% (Stubenrauch et al. 2013, their Fig. 1).

The difference distributions between the filtered MODIS and merged-IR products are slightly positively skewed in the NE Pacific and SE Atlantic, which means that the merged-IR product tends to slightly underestimate cloudiness in these regions. We marginally overestimate cloudiness in the SE Pacific where the distributions are negatively skewed. Within a given region, the difference distributions for each of the three boxes have the same shape and a large degree of overlap, and we thus conclude that that there is no apparent regional east-west bias in the cloud-identification method.

We can illustrate the time of day at which the larger differences occur by separately computing the difference distributions for daytime and nighttime MODIS overpasses (Fig. 9). There is a slight tendency for the mergedIR product to underestimate cloud fraction during the day. This tendency is largest in the NE Pacific and SE Atlantic, where the tails of the difference distributions between $+10 \%$ and $+20 \%$ have higher frequencies than for the other distributions (Figs. 9a,e). In addition, Fig. 9 shows that the width of the difference distribution is larger during the daytime scenes, indicating slightly weaker agreement between the two products during the day than at night. The discrepancy between daytime and nighttime scenes is likely due to a combination of the use of $250-\mathrm{m}$ (nadir) visible-spectrum data in daytime MODIS cloud fraction retrievals and the fact that the cloud deck is more broken during the day than at night (Turton and Nicholls 1987; Betts 1990; de Szoeke et al. 2012). The MODIS daytime cloud fraction retrieval is less subject to the influence of partially filled pixels than are the MODIS nighttime product or the merged-IR retrieval.

To test the sensitivity in low cloud fraction regions where partially filled pixels are more likely to occur, we can evaluate the frequency of differences between the filtered MODIS and merged-IR total areal cloud fractions conditioned on the filtered MODIS cloud fraction (Fig. 10). If our retrieval method is flawed in regions of broken cloud, then this weakness will show up as larger 


\section{0\% Too Low IR Temperature}

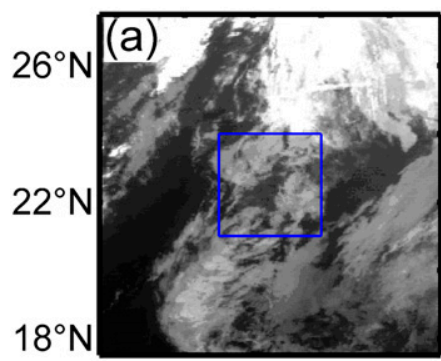

IR Cloud Mask

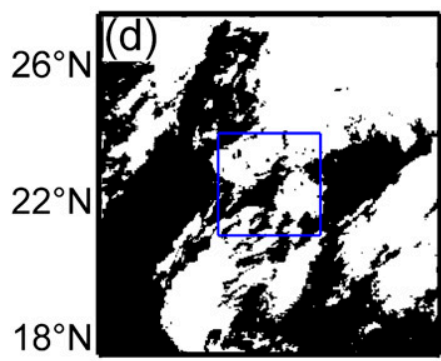

MODIS Mask

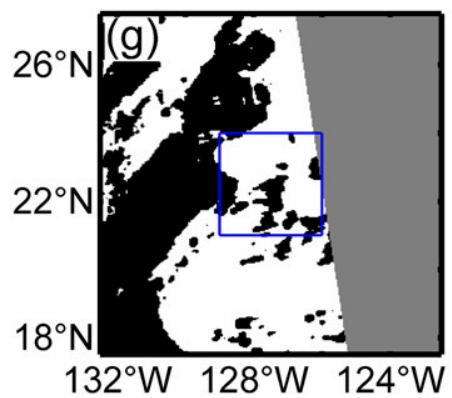

Close Match IR Temperature

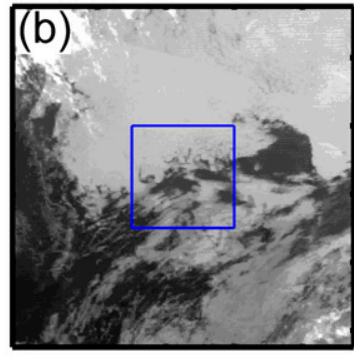

IR Cloud Mask

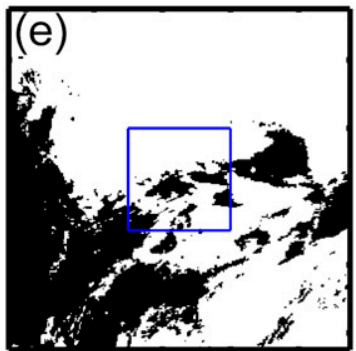

MODIS Mask

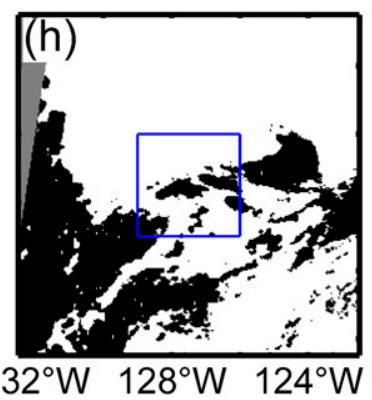

10\% Too High
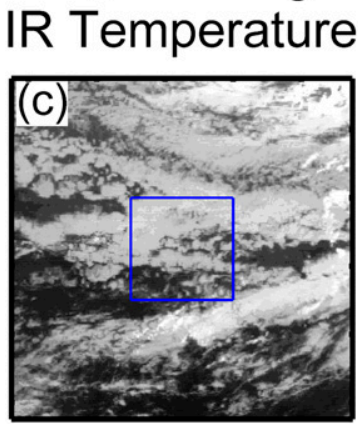

$295 \mathrm{~K}$

$290 \mathrm{~K}$

$285 \mathrm{~K}$

$280 \mathrm{~K}$

275 K
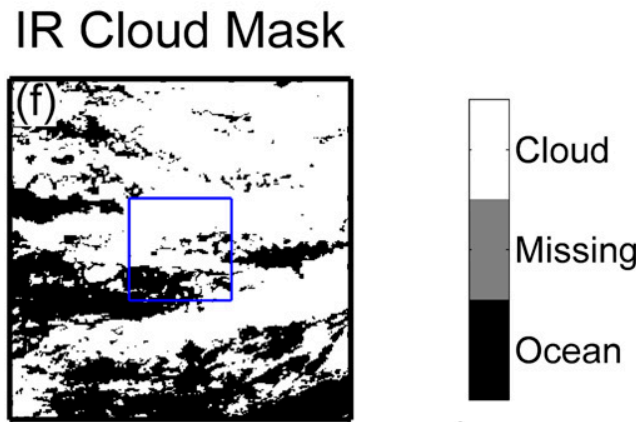

\section{MODIS Mask}

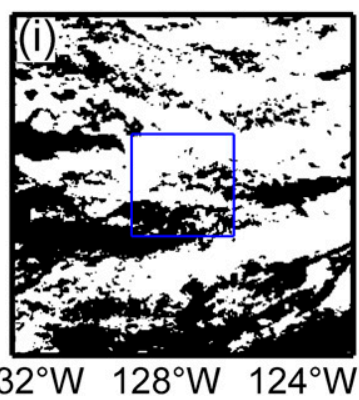

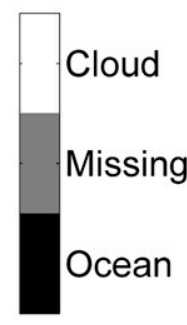

FIG. 7. Example scenes from the NE Pacific for which the merged-IR cloud-identification method (left) underestimates total cloud fraction by $10 \%$ (2200 UTC 8 Jan 2004), (center) is a close match (0930 UTC 8 Jan 2004), and (right) overestimates cloud fraction by $10 \%$ (1000 UTC 4 Jan 2004) relative to the filtered MODIS total cloud fraction. (a)-(c) The merged-IR Tb, and the (d)-(f) merged-IR and (g)-(i) filtered MODIS cloud masks. MODIS pixels with fractional cloudiness $>87 \%$ are classified as cloud to create a more direct binary comparison (section 3b).

differences between the two products in areas where the filtered MODIS cloud fraction is relatively low. For any given filtered MODIS areal cloud fraction, the frequency distribution of differences is tightly clustered around $0 \%$ (Fig. 10). The mean difference between the two products is within $\pm 10 \%$ for any situation in which clouds are present. One exception is the merged-IR estimates of areal cloud fraction for filtered MODIS cloud fractions of less than $1 \%$ where the mean difference is larger than $10 \%$. This scenario occurs less than $3 \%$ of the time in any of the subtropical marine stratocumulus regions. This information indicates that the merged-IR cloud fraction method performs well at nearly the full range of observed cloud fractions.
We compare the spatial patterns of temporal cloud fraction using maps of diurnal mean cloud fraction computed using only the merged-IR times that are closest to the four MODIS overpasses (Figs. 11 and 12). These maps show very similar spatial patterns and frequencies of cloud fraction between the merged-IR and filtered MODIS products at night (MODIS overpasses near 2230 and 0130 LT; Fig. 11). During the daytime (MODIS overpasses near 1030 and 1330 LT; Fig. 12), the spatial patterns are similar, but the merged-IR retrieval underestimates cloud fraction relative to filtered MODIS near the center of the cloud decks by up to $10 \%-15 \%$ in the NE Pacific and SE Atlantic (Figs. 12c,i). For the SE Pacific, the daytime maps have similar 

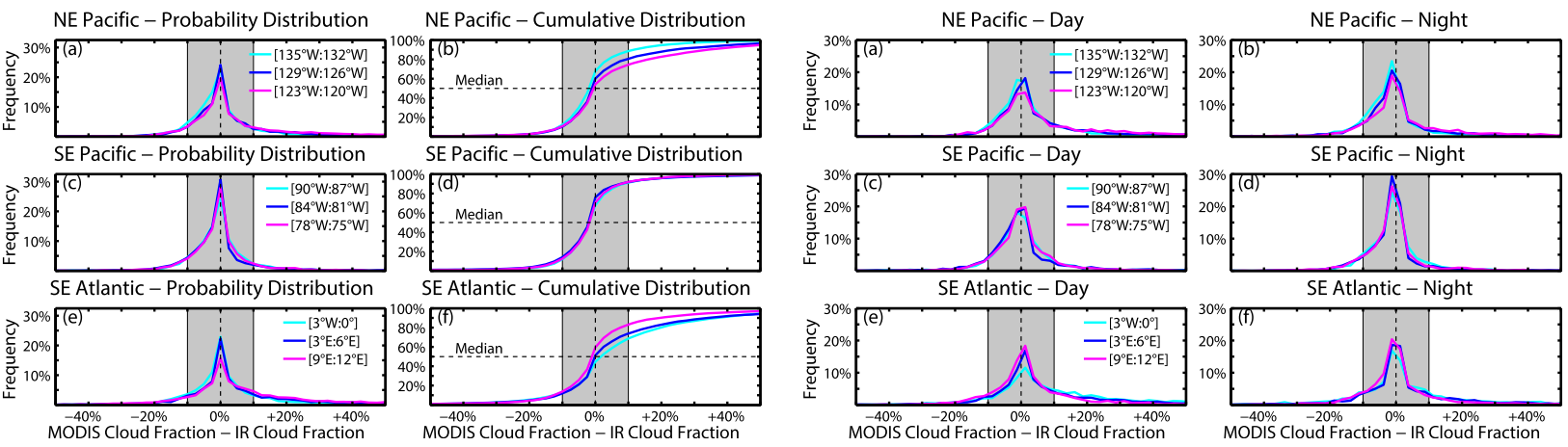

FIG. 8. (left) Probability and (right) cumulative distributions of the difference between the filtered MODIS and merged-IR total cloud fraction for multiple $3^{\circ} \times 3^{\circ}$ boxes spanning an east-west gradient in the (a),(b) NE Pacific $\left(21^{\circ}-24^{\circ} \mathrm{N}\right)$, (c),(d) SE Pacific $\left(21^{\circ}-18^{\circ} \mathrm{S}\right)$, and (e),(f) SE Atlantic $\left(15^{\circ}-12^{\circ} \mathrm{S}\right)$. Distributions are obtained from approximately 5000 MODIS overpasses for each region between 2003 and 2010. The gray-shaded region indicates values that are within $\pm 10 \%$ of the filtered MODIS value.

cloud fraction magnitudes near the center of the cloud deck (Fig. 12f). A similar comparison using the unfiltered MODIS cloud fraction values is given in Figs. S2 and S3 in the online supplemental material. The unfiltered MODIS data have a similar-amplitude diurnal cycle and also maintain the spatial structure evident in the filtered MODIS dataset (Figs. S4-S6 in the online supplement).

In Figs. S7-S9 of the online supplement we compare the filtered MODIS and merged-IR total cloud fraction for each season [June-August (JJA), SeptemberNovember (SON), December-February (DJF), and

FIG. 9. As in Figs. 8a,c,e, but for (left) daytime and (right) nighttime overpasses.

March-May (MAM)] in all three regions. The mergedIR product is able to capture the amplitude in the seasonal variability of cloud fraction in each region as well as the significant changes to the geographic pattern of the cloud deck across the seasons. The difference distribution and map comparisons with filtered MODIS cloud fractions indicate that the merged-IR product performs best for the SE Pacific marine stratocumulus region and will tend to slightly underestimate daytime cloudiness in the SE Atlantic and NE Pacific. We will keep these limitations in mind in the interpretation of the analysis on the basis of the merged-IR cloud fraction product. Although the evaluations of our cloud masks demonstrate that our method for defining the ST is robust, there are likely instances in which our best-guess separation temperatures may be off by $\pm 1 \mathrm{~K}$. Biases of $\pm 1 \mathrm{~K}$ can change the mean IR cloud fraction by up to
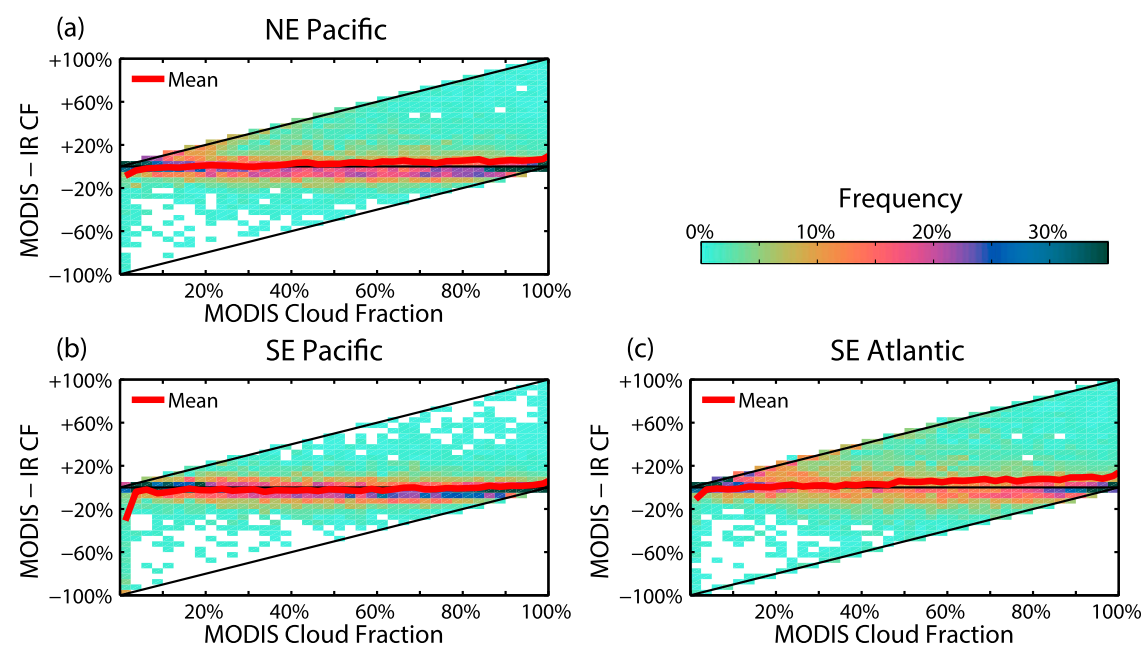

FIG. 10. Data-density diagrams showing the frequency of occurrence of differences between the filtered MODIS and merged-IR total cloud fraction (labeled as CF) conditioned on the value of the filtered MODIS cloud fraction in $3^{\circ} \times 3^{\circ}$ boxes. Each plot is based on five $3^{\circ} \times 3^{\circ}$ boxes in each region for 2003-10 in the (a) NE Pacific, (b) SE Pacific, and (c) SE Atlantic. Darker colors indicate more frequent occurrences. The solid red line in each plot indicates the mean difference for a given MODIS cloud fraction. 


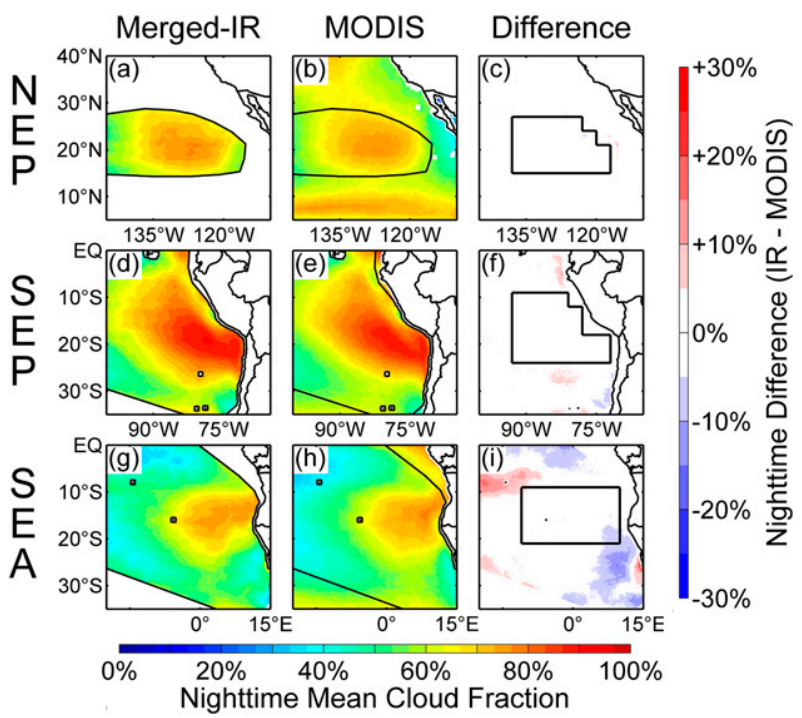

FIG. 11. (left) Mean merged-IR total cloud fraction, (center) filtered MODIS total cloud fraction, and (right) the difference between the two (IR - MODIS) at night in the (a)-(c) NE Pacific, (d)-(f) SE Pacific, and (g)-(i) SE Atlantic. Data were aggregated from approximately 5000 MODIS overpasses across all seasons from 2003 to 2010 . The merged-IR data were taken from the 30-min scene closest to each MODIS nighttime ( 2230 and 0130 LT) overpass. The solid lines in the left and center columns delineate the regions of merged-IR data that do not contain an obvious zenith-angle-correction error and where MODIS cloud-top temperatures colder than $273 \mathrm{~K}$ occur less than $35 \%$ of the time. In the right column, black lines outline the areas used in our quantitative analyses.

$\pm 5 \%$ and the amplitude of the diurnal cycle by the same magnitude but do not substantially alter either the geographic locations or timing of diurnal or seasonal low-cloud variability (see the appendix).

Our analysis is based in part on separating results for the maximum and minimum cloudiness season in each region. We objectively defined the maximum and minimum cloudiness season for each $4 \mathrm{~km} \times 4 \mathrm{~km}$ pixel location and then determined which season was predominant in an areal average of the $4 \mathrm{~km} \times 4 \mathrm{~km}$ pixels over each study region (see Figs. S10-S12 in the supplemental material) using both the filtered MODIS and merged-IR cloud fractions.

Although our geographic study areas are not identical to those of Klein and Hartmann (1993), our maximum and minimum cloudiness seasons for the SE Pacific (SON and DJF) and the SE Atlantic (SON and MAM) match their findings. The seasonal cycle has smaller amplitude in the NE Pacific than in the SE Pacific or SE Atlantic. In addition, in the NE Pacific region there is a latitudinal variation of the season when minimum and maximum cloudiness occur. Klein and Hartmann (1993) used $5^{\circ} \times 5^{\circ}$ data for their analysis and defined their NE

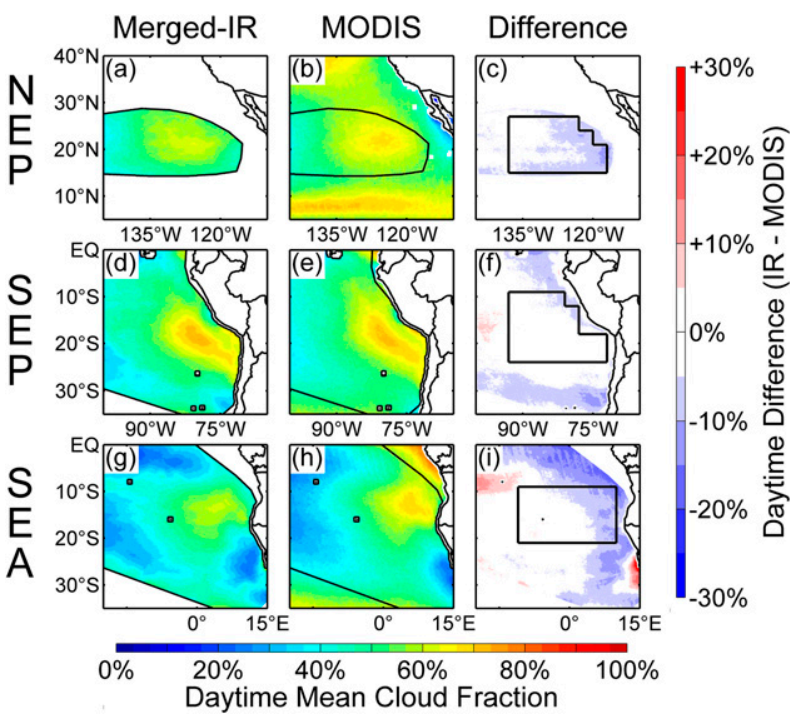

FIG. 12. As in Fig. 11, but for the MODIS daytime ( $\sim 1130$ and 1330 LT) overpasses.

Pacific region of interest as the box bounded by $20^{\circ}$ $30^{\circ} \mathrm{N}$ and $120^{\circ}-130^{\circ} \mathrm{W}$ (Klein and Hartmann 1993, their Table 1). They found the peak stratus cloudiness season in the NE Pacific to be JJA and the minimum season to be DJF. Our analysis uses $4 \mathrm{~km} \times 4 \mathrm{~km}$ data and a region slightly to the south, from $15^{\circ}$ to $27^{\circ} \mathrm{N}$ and from $117^{\circ}$ to $138^{\circ} \mathrm{W}$. For our region of interest in the NE Pacific, the peak season is MAM and the minimum season is SON. The differences in the peak and minimum seasons are primarily the result of the different regions examined (see Fig. S10 in the supplemental material). Since the amplitude of the seasonal cycle in the NE Pacific is weak, use of Klein and Hartmann's (1993) JJA and DJF as the maximum and minimum cloudiness seasons for the NE Pacific does not significantly change our findings regarding differences between maximum and minimum season cloudiness characteristics.

\section{Results}

\section{a. Areal patterns and the diurnal cycles of cloud fraction}

We compare several facets of the subtropical marine stratocumulus diurnal cycle among seasons and geographic regions. The spatial patterns of mean cloud fraction across the diurnal cycle during the maximum cloudiness season for each of the three regions are shown in Figs. 13-15. The evolving cloud fields are best viewed as a movie loop (and are included as such in the online supplemental material) but are shown here as static images. At a few times of day there are data artifacts in the hourly mean plots that appear as subtle 

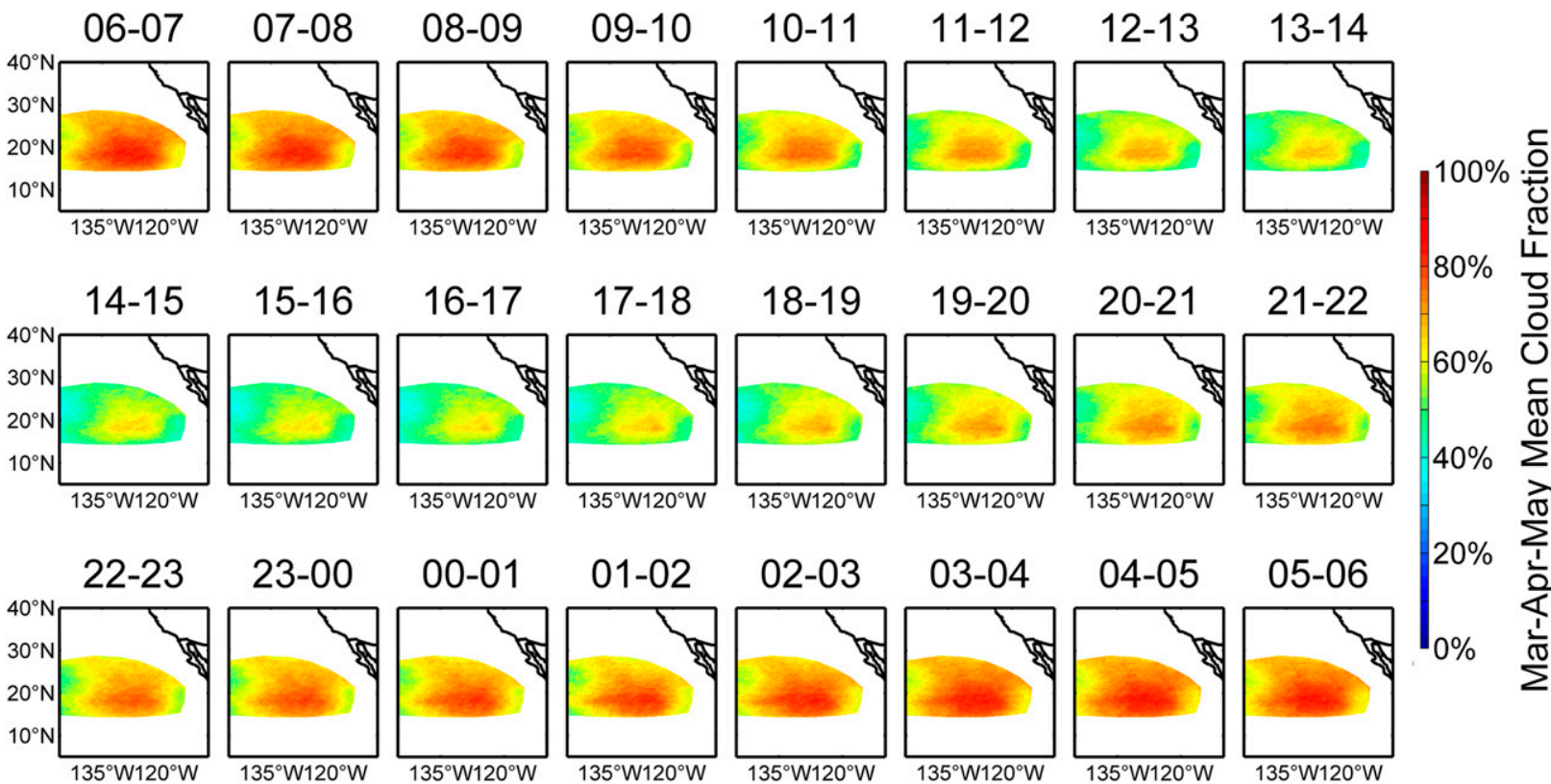

FIG. 13. Hourly mean merged-IR cloud fraction across the diurnal cycle during the maximum cloudiness season in the NE Pacific (MAM). The local solar time for each 1-h window is indicated at the top of the box. Data were aggregated from 2003 to 2010, and each 1-h period contains approximately 1500 scenes.

vertical striping in both the SE Pacific and SE Atlantic (Figs. 14 and 15). These artifacts occur outside the regions used for the quantitative portion of our analysis (blue boxes in Fig. 3) and thus do not affect our results. The data artifacts are related to intermittent bad data in the 30-min IR Tb dataset that we were unable to filter without compromising large amounts of good data. The striping artifacts are most noticeable from 2300 to $0100 \mathrm{LT}$ near $5^{\circ} \mathrm{S}$ and $80^{\circ}-90^{\circ} \mathrm{W}$ in the SE Pacific (Fig. 14) and from 1100 to $1200 \mathrm{LT}$ and from 2300 to $0200 \mathrm{LT}$ near $10^{\circ}-20^{\circ} \mathrm{S}$ and $10^{\circ} \mathrm{W}$ in the SE Atlantic (Fig. 15).

The overall temporal variability of the spatial patterns of cloudiness resembles pulsing-contracting toward the center of the cloud field during much of the day and
06-07

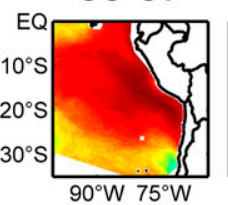

14-15

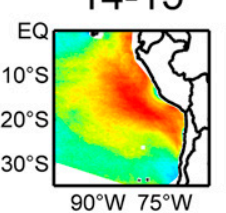

22-23

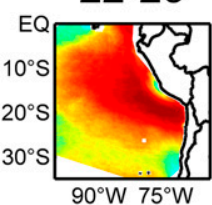

07-08

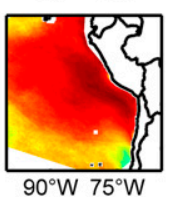

15-16

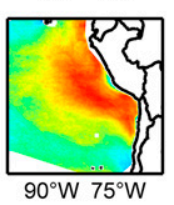

23-00

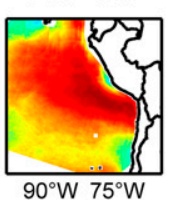

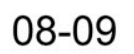

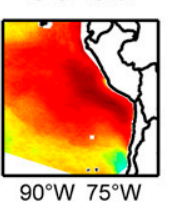

16-17
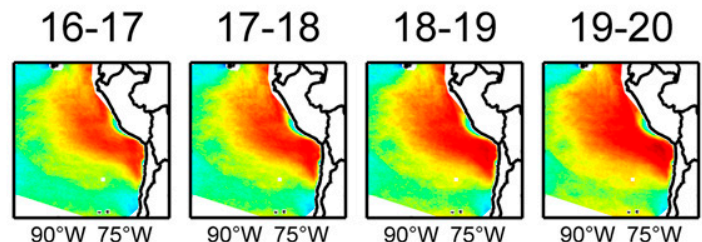

00-01
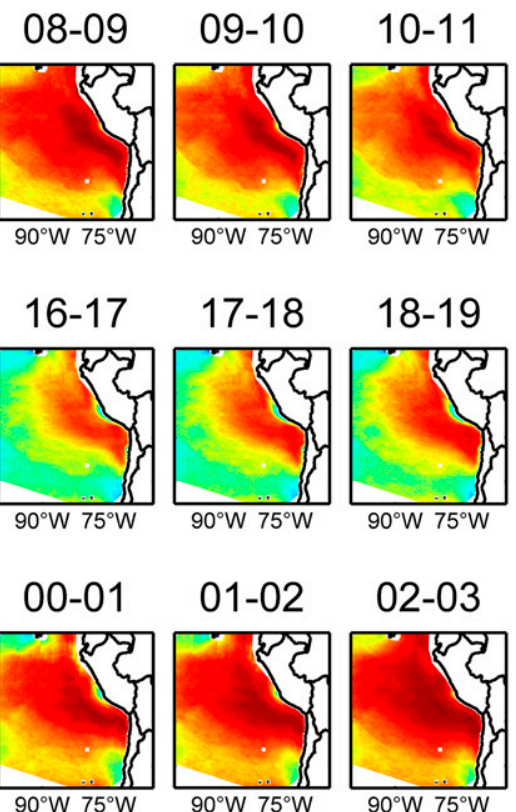
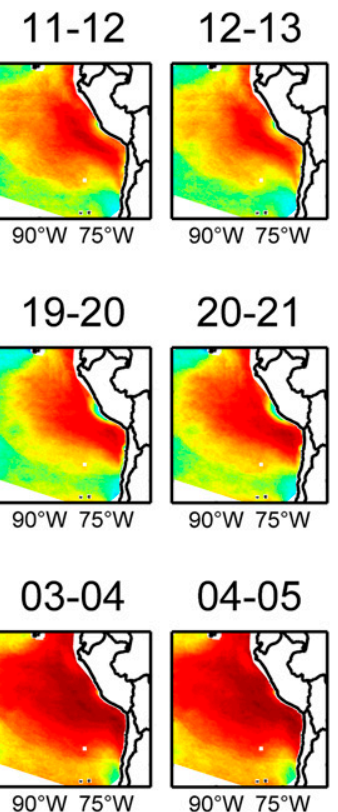

$90^{\circ} \mathrm{W} 75^{\circ} \mathrm{W}$ )

FIG. 14. As in Fig. 13, but for the SE Pacific (SON).
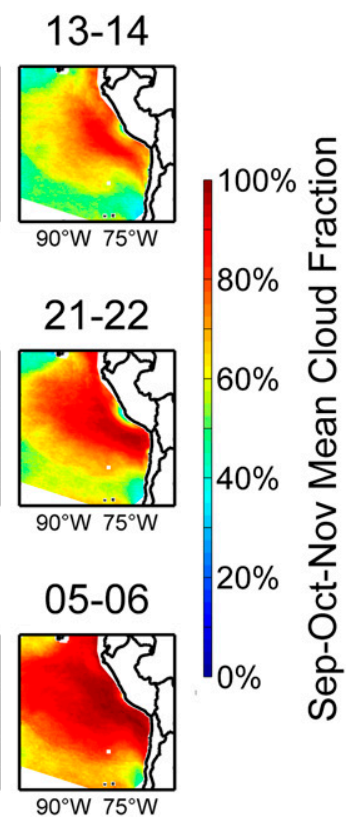

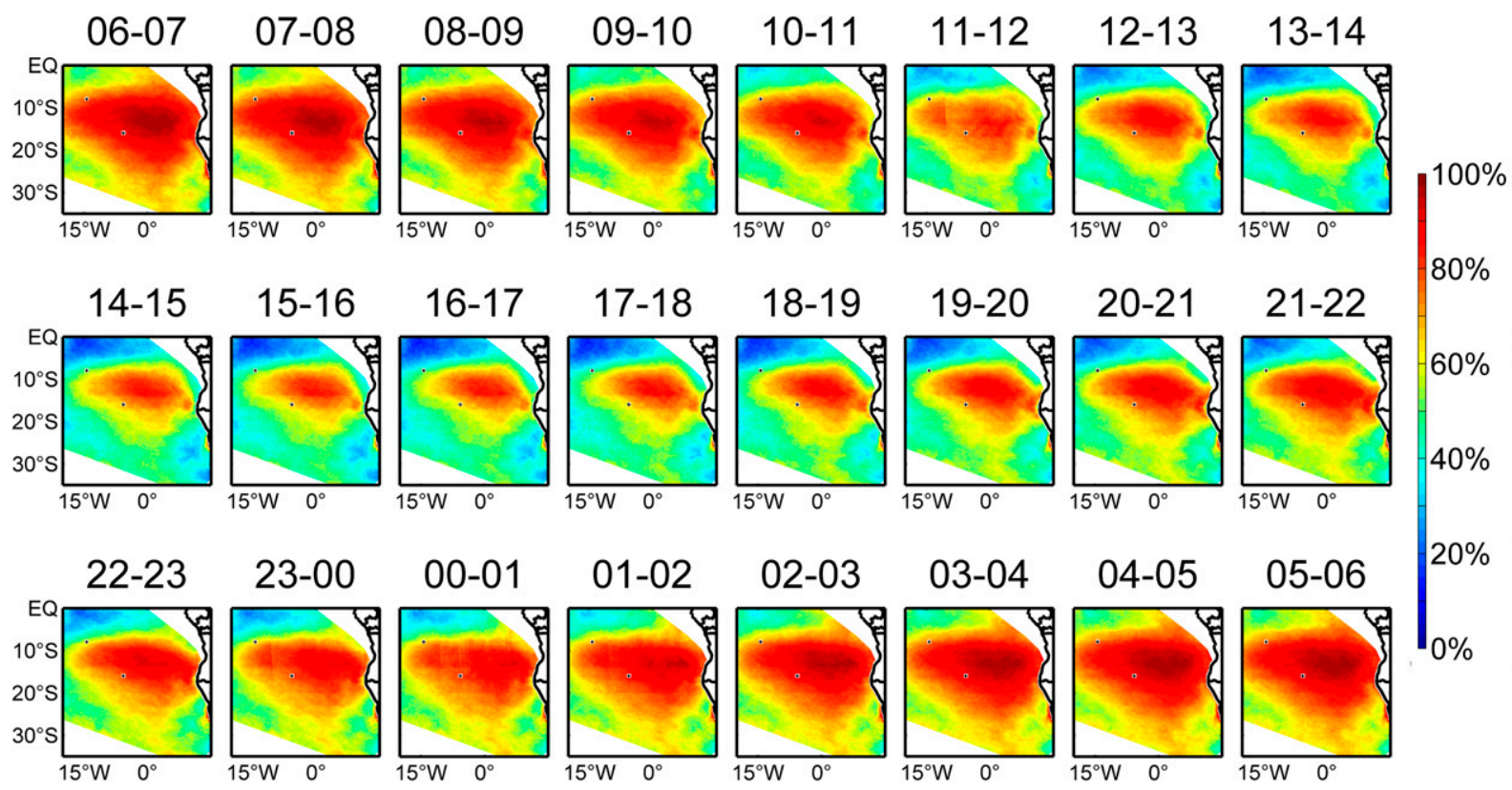

FIG. 15. As in Fig. 13, but for the SE Atlantic (SON).

expanding away from the center overnight. We show only the patterns during the maximum cloudiness season in each region to remove one source of temporal variability, the seasonal cycle, from our analysis of diurnal variability. In general, patterns of cloud fraction variability during the minimum cloudiness season are less robust and are noisier. We attribute this behavior to the fact that the cloud deck behaves less like a classical stratocumulus-topped boundary layer during periods of weaker stability. For this reason, much of our analysis will focus only on the maximum cloudiness season within each region.

In all three regions, the mean low cloud fraction is maximized between 0500 and 0700 LT (approximately sunrise) and reaches a diurnal minimum between 1500 and 1700 LT (e.g., Turton and Nicholls 1987; Klein et al. 1995; Rozendaal et al. 1995; de Szoeke et al. 2012). After 1500-1700 LT, cloud fraction gradually increases back to its diurnal peak value just before sunrise. Regions of lower cloud fraction near the edge of the cloud deck have higher rates of change of cloud fraction, both during the day and night, than do regions of higher cloud fraction closer to the center of the cloud deck. As a result, the largest daily variations in cloud fraction in each region are along the edges of the cloud deck (Fig. 16). This result is consistent with Rozendaal et al. (1995, their Fig. 9), who showed that larger-amplitude diurnal cycles occur along the edges and in lower cloud fraction areas of the subtropical marine stratocumulus cloud decks. Painemal et al. (2015, their Fig. 10c) documented a similar pattern for the peak cloudiness season in the
SE Atlantic. In the center of the cloud deck, the difference in the maximum and minimum hourly mean cloud fraction is less than $20 \%$. In deeper boundary layers farther from the coast in the SE Pacific and SE Atlantic, cloud fractions can vary by as much as $40 \%$ across the diurnal cycle. Diurnal variations in cloudiness are the result of the superposition of fewer factors over the open ocean than near the coast. Clouds near the coast are also influenced by dynamic processes associated with diurnal heating of the land surface, prevailing winds interacting with coastal topography, and aerosol concentrations that are higher than in open-ocean areas (Garreaud and Muñoz 2004; Rahn and Garreaud 2010; Wood et al. 2009; Wyant et al. 2010).

While each region has its unique characteristics, the spatial patterns of diurnal variation in cloudiness are generally more similar between the SE Pacific and SE Atlantic than between the SE Pacific and the NE Pacific (Figs. 13-16). This provides some context for the results of Painemal et al. (2015), who documented differences between the diurnal cycle characteristics of marine stratocumulus in the SE Pacific and SE Atlantic. Our analysis indicates that the differences between the SE Pacific and SE Atlantic are smaller than the differences between the two Southern Hemisphere stratocumulus decks and the one in the NE Pacific. Although our analysis of the NE Pacific is hampered by issues that limit the region for which our simple low cloud mask works (see section 3), we observed one noticeable difference in the maps: the spatial gradient in cloud fraction is weaker and somewhat more diffuse near the center of 

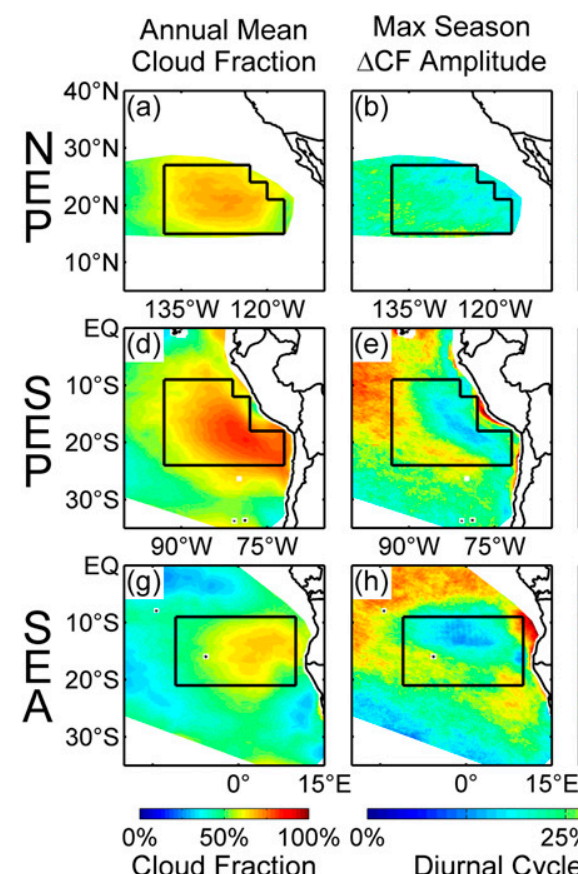

Min Season $\triangle$ CF Amplitude
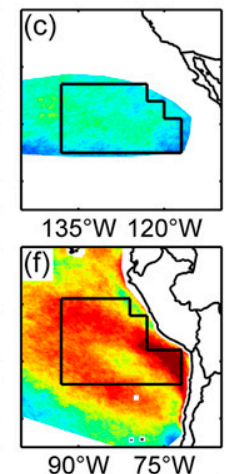

FIG. 16. Annual mean merged-IR low cloud fraction in the (a) NE Pacific, (d) SE Pacific, and (g) SE Atlantic. Amplitude of the diurnal cycle of cloud fraction during the maximum cloudiness season in the (b) NE Pacific (MAM), (e) SE Pacific (SON), and (h) SE Atlantic (SON) and during the minimum cloudiness season in the (c) NE Pacific (SON), (f) SE Pacific (DJF), and (i) SE Atlantic (MAM). The amplitude is the difference between the maximum and minimum hourly mean cloud fractions at any point during the day. Data were aggregated from 2003 to 2010.

the cloud deck in the NE Pacific than in the other two regions. In some cases, the largest-amplitude diurnal cycles can extend outside of our defined stratocumulus regions (Fig. 16). Rozendaal et al. (1995, their Figs. 9 and 10) showed that the largest-amplitude diurnal cycles in the NE Pacific occur closer to $20^{\circ} \mathrm{N}$ and $140^{\circ} \mathrm{W}$, an area that is characterized as a stratocumulus-to-cumulus transition region [e.g., Sandu and Stevens (2011) and references therein] and is just west of our defined stratocumulus domain. Since we do not have enough information to fully characterize the environment, we cannot explain the differences entirely. In a follow-on paper we speculate that the smaller-amplitude diurnal cycle and smaller seasonal variability in the cloud fraction diurnal cycle in the NE Pacific are related to the closer proximity of and hence stronger multiday timescale influences from the extratropical storm track and the ITCZ, which act to disturb the environment (Burleyson and Yuter 2015).

Regional differences can be better quantified by examining the distributions of areal cloud fraction by time of day and for the maximum and minimum cloudiness seasons for each region (Fig. 17). Figure 17 was computed by aggregating areal cloud fraction over each $3^{\circ} \times 3^{\circ}$ area (blue boxes in Fig. 3) in each scene over 2003-10. We filtered the mean values using a 3 -h running mean filter to remove anomalous spikes in the distribution of cloud fraction due to intermittent and random anomalies in the dataset. The areal cloud fraction between subsequent 30-min scenes can be used to calculate a rate of change of cloud fraction across the diurnal cycle (Fig. 18).

During maximum cloudiness seasons, the amplitude of the diurnal variation in cloud fraction is similar among the regions and is approximately sinusoidal in time after accounting for the limit behavior near cloud fractions of $100 \%$ (Figs. 17a,c,e). During the maximum season, the SE Pacific and SE Atlantic have narrower distributions of cloud fraction and higher cloud fractions in the mean and the 10th and 90th percentiles than does the NE Pacific (Figs. 17a,c,e). The rate of cloud breakup maximizes at local solar noon and is strongly dependent on the downwelling solar radiative flux (Fig. 18 and section $4 b$ ).

The SE Atlantic exhibits the largest difference between maximum and minimum cloudiness seasons and has the lowest mean daytime cloud fractions during the minimum cloudiness season (Fig. 17f). During the minimum cloudiness season, the amplitude of the mean diurnal cloud fraction variation is largest in the SE Pacific, $\sim 35 \%$ between 0600 and 1500 LT as compared with $19 \%$ in the NE Pacific and $23 \%$ in the SE Atlantic. This feature of the SE Pacific is consistent with the climatological description of Eastman and Warren (2014, their Fig. 7). Surprising is that the diurnal variability in the minimum cloudiness season in the SE Atlantic is not only weak but is less sinusoidal than that for the other regions and seasons (Fig. 17f). The SE Atlantic cloud fraction diurnal cycle appears to "flatten out" between 1200 and 1800 LT, inconsistent with solar forcing. Some additional forcing, perhaps aerosols or large-scale dynamics, is playing a role, but it is beyond the scope of this paper to investigate it further.

\section{b. Conditional changes in cloud fraction}

The effect of initial cloud fraction on subsequent changes to the cloud is illustrated in Figs. 19 and 20, which show the evolution of cloud fraction conditioned on cloud fraction at dawn or dusk for a $10^{\circ} \times 10^{\circ}$ area (green boxes in Fig. 3) centered over each cloud deck. We focus on the regional-scale (i.e., $10^{\circ} \times 10^{\circ}$ ) cloudiness evolution because the dependency on initial cloud fraction is likely to be noisier and harder to detect on smaller scales at which any number of factors may influence cloud fraction on time scales approaching $12 \mathrm{~h}$. Using a larger box also minimizes the impact of horizontal advection on our analysis. At typical cloud-level 

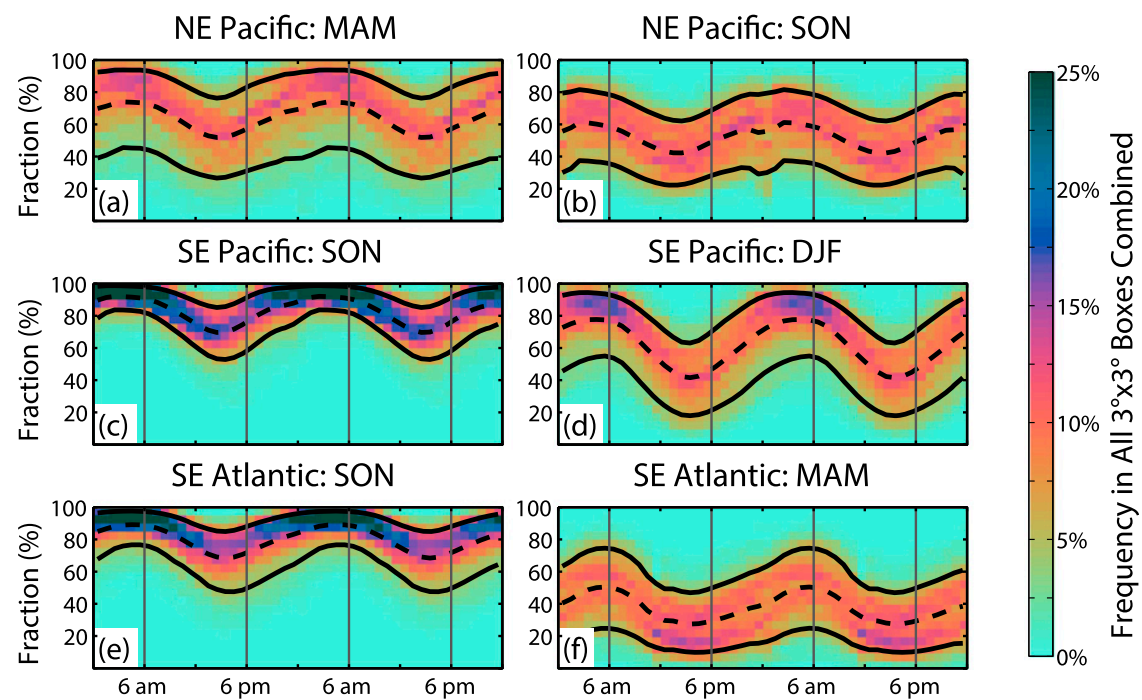

FIG. 17. Data-density diagrams showing the frequency distributions of low cloud fraction across the diurnal cycle during the (left) maximum and (right) minimum cloudiness seasons in the (a),(b) NE Pacific, (c),(d) SE Pacific, and (e),(f) SE Atlantic. Cloud fractions are the total low cloud fraction in the $3^{\circ} \times 3^{\circ}$ boxes shown in blue in Fig. 3. Darker colors indicate more frequent occurrences. In all panels, the center black line indicates the hourly mean and the outer black lines indicate the 10th and 90th percentiles of the hourly distribution. The $x$ axis is repeated twice for clarity, and the approximate times of sunrise and sunset are shown by the vertical gray lines. Data are smoothed using a 3-h running-mean filter to remove artifacts associated with intermittent gaps in the 30-min IR dataset.

wind speeds of $\sim 7 \mathrm{~m} \mathrm{~s}^{-1}$, clouds move approximately $300 \mathrm{~km}$ in $12 \mathrm{~h}$. This advection distance is much smaller than the area that we are analyzing, and therefore our Eulerian analysis does not differentiate between cloud breakup in place and advection. We use data from all seasons in this analysis to capture a wider range of starting cloud fractions at dawn or dusk than would be available if we only utilize the maximum or minimum cloudiness season in each region.

During the day, there is a clear signal that regions with broken clouds at dawn have faster rates of cloud breakup between 0600 and 1200 LT than do regions in which the cloud deck is overcast when the sun comes up (slopes of the black lines in Fig. 19; see also Table 1).

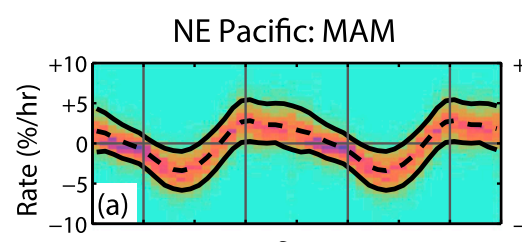

SE Pacific: SON
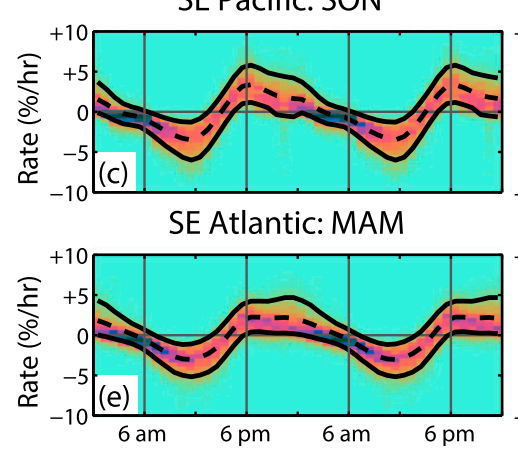

NE Pacific: SON

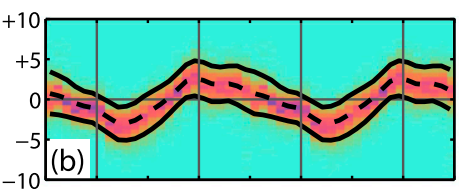

SE Pacific: DJF

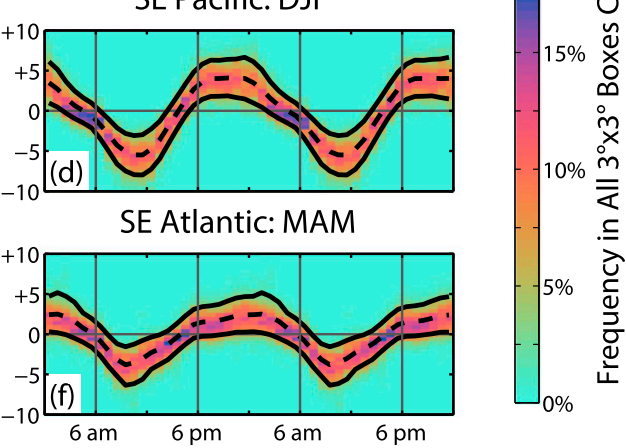

FIG. 18. As in Fig. 17, but for the rate of change of low cloud fraction between subsequent 30-min scenes. 

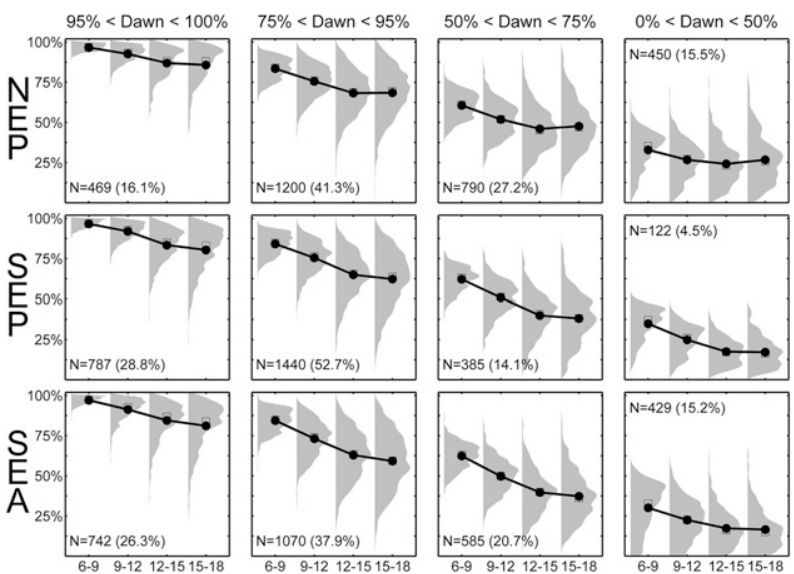

FIG. 19. Distributions of cloud fraction ( $y$ axis) during the daylight hours conditioned on cloud fraction at dawn (0500-0600 LT) for each of the three marine stratocumulus regions. Distributions of mean cloud fractions are shown for 3-h time windows. Starting dawn cloud fractions are (left) greater than $95 \%$, (center left) between $75 \%$ and $95 \%$, (center right) between $50 \%$ and $75 \%$, and (right) less than $50 \%$. For each distribution, the filled circle shows the mean value and the open square shows the median value. Total sample size $N$ and sample fraction (\%) are given in each panel. Data are shown for the (top) NE Pacific, (middle) SE Pacific, and (bottom) SE Atlantic. Cloud fractions for each region were calculated for every day from 2003 to 2010 in the $10^{\circ} \times 10^{\circ}$ boxes delineated by green lines in Fig. 3 .

After 1200 LT, rates of cloud breakup are smaller. The rate of change of cloud fraction in the early morning hours is slower if the cloud fraction at dawn is greater than $95 \%$ than if the dawn cloud fraction is less than $95 \%$. This pattern holds even if we separate the maximum and minimum cloudiness season in each region to account for differences in the magnitude of the

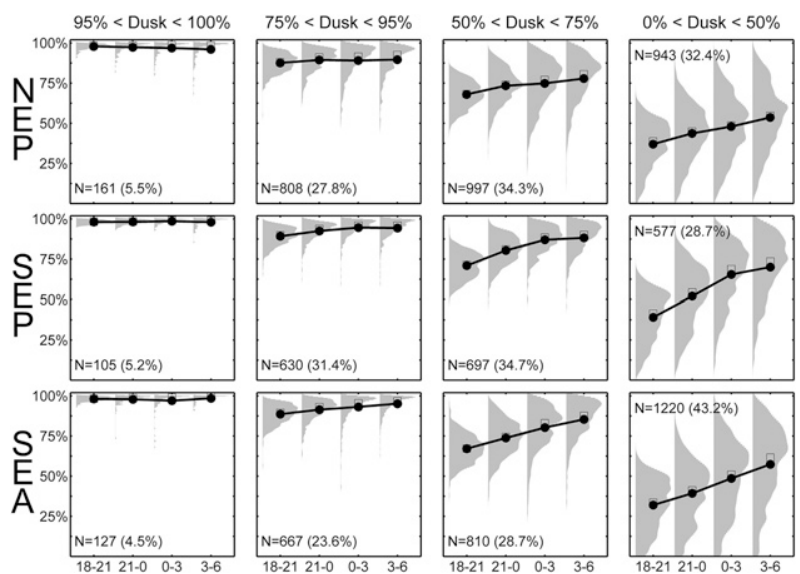

FIG. 20. As in Fig. 19, but for distributions of cloud fraction overnight conditioned on cloud fraction at dusk (1700-1800 LT).

downwelling solar flux in each season (Figs. S16-18 in the supplemental material). The rate of cloud breakup in the minimum cloudiness season is somewhat faster owing to an increase in the downwelling solar flux. Rates of change for a given starting cloud fraction condition and time are nearly all within $2 \% \mathrm{~h}^{-1}$ among the regions (Table 1). For a given cloud condition at dawn, the NE Pacific has the slowest rates of cloud breakup during the day. The overall trend at night is for cloud fraction to increase except for the limit behavior of dusk cloud fractions $>95 \%$, which stay near $100 \%$ overnight (Fig. 20). Of the three regions, the NE Pacific has slightly more skewed distributions at 0300-0600 LT for dusk cloud fractions $<50 \%$, indicating a slightly higher but still very low probability for cloud fraction to decrease at night in the NE Pacific relative to the other regions.

TABLE 1. Mean rate of change $\left(\% \mathrm{~h}^{-1}\right)$ of cloud fraction (labeled as CF) during the day (left three columns) and overnight (right three columns) conditioned on the cloud fraction at dawn and dusk in the NE Pacific (labeled as NEP), SE Pacific (labeled as SEP), and SE Atlantic (labeled as SEA).

\begin{tabular}{|c|c|c|c|c|c|c|}
\hline & 0600-1200 LT & 0900-1500 LT & 1200-1800 LT & $1800-0000 \mathrm{LT}$ & $2100-0300 \mathrm{LT}$ & 0000-0600 LT \\
\hline & \multicolumn{3}{|c|}{$95 \%<\mathrm{CF}$ at dawn $<100 \%$} & \multicolumn{3}{|c|}{$95 \%<\mathrm{CF}$ at dusk $<100 \%$} \\
\hline NEP & -1.3 & -1.9 & -0.4 & -0.2 & -0.2 & -0.3 \\
\hline SEP & -1.6 & -2.9 & -1.0 & 0.0 & 0.1 & -0.2 \\
\hline \multirow[t]{2}{*}{ SEA } & -1.9 & -2.3 & -1.1 & -0.1 & -0.3 & 0.5 \\
\hline & \multicolumn{3}{|c|}{$75 \%<\mathrm{CF}$ at dawn $<95 \%$} & \multicolumn{3}{|c|}{$75 \%<\mathrm{CF}$ at dusk $<95 \%$} \\
\hline NEP & -2.6 & -2.4 & 0.1 & 0.6 & -0.1 & 0.2 \\
\hline SEP & -2.9 & -3.5 & -0.9 & 1.1 & 0.7 & -0.1 \\
\hline \multirow[t]{2}{*}{ SEA } & -3.8 & -3.4 & -1.2 & 0.9 & 0.6 & 0.7 \\
\hline & \multicolumn{3}{|c|}{$50 \%<\mathrm{CF}$ at dawn $<75 \%$} & \multicolumn{3}{|c|}{$50 \%<\mathrm{CF}$ at dusk $<75 \%$} \\
\hline NEP & -2.9 & -2.0 & 0.6 & 1.8 & 0.5 & 1.0 \\
\hline SEP & -3.8 & -3.6 & -0.6 & 3.1 & 2.2 & 0.4 \\
\hline \multirow[t]{2}{*}{ SEA } & -4.2 & -3.4 & -0.8 & 2.2 & 2.2 & 1.7 \\
\hline & \multicolumn{3}{|c|}{$\mathrm{CF}$ at dawn $<50 \%$} & \multicolumn{3}{|c|}{$\mathrm{CF}$ at dusk $<50 \%$} \\
\hline NEP & -2.1 & -0.8 & 0.8 & 2.2 & 1.4 & 1.9 \\
\hline SEP & -3.4 & -2.4 & -0.1 & 4.3 & 4.5 & 1.5 \\
\hline SEA & -2.5 & -1.7 & -0.3 & 2.4 & 3.1 & 2.9 \\
\hline
\end{tabular}




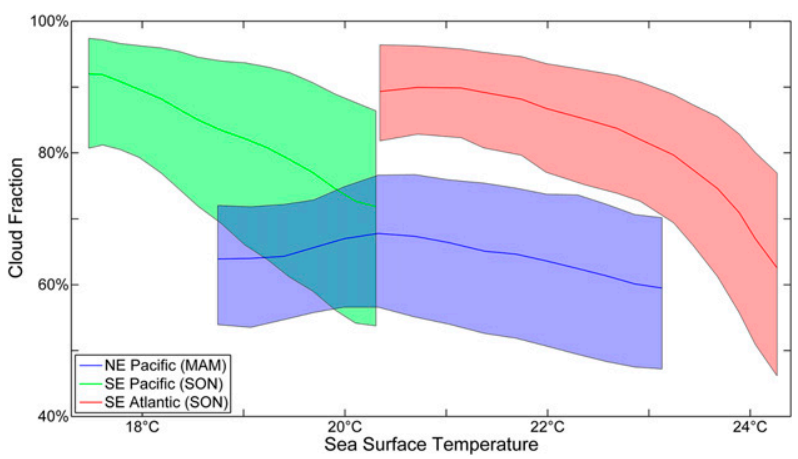

FIG. 21. Seasonal mean low cloud fraction (solid lines) and range between the maximum and minimum hourly mean low cloud fractions (shaded regions) conditioned on SST ( $x$ axis) for the maximum cloudiness season in the NE Pacific (MAM; blue), SE Pacific (SON; green), and SE Atlantic (SON; red). The data for each region are based on cloud properties within fifteen $1^{\circ} \times 3^{\circ}$ boxes starting from the center of the cloud deck and continuing along a line perpendicular to the primary SST gradient.

Stratocumulus cloud fraction has previously been shown to be dependent on boundary layer depthdeeper boundary layers are associated with lower mean cloud fractions as the cloud-topped boundary layer regime makes a transition from stratocumulus to trade cumulus (Bretherton and Wyant 1997; Wood and Hartmann 2006; Mechem et al. 2012). To what degree is the amplitude of the diurnal variation in cloud fraction controlled by boundary layer depth? We can investigate this question by using the seasonal mean SST as a proxy for boundary layer depth (Wood and Bretherton 2004; Leon et al. 2008; Zuidema et al. 2009; de Szoeke et al. 2012) and tabulating cloud fraction properties from the center of the cloud deck outward away from the coast (Fig. 21). As expected, the mean cloud fraction decreases as SST increases (boundary layer depth increases). The mean cloud fraction decreases about $10 \%$ for each $1^{\circ} \mathrm{C}$ of SST change for all three regions (Fig. 21). The amplitude of the diurnal cycle also generally increases with increasing SST and decreasing mean cloud fraction. This effect is most prominent in the SE Pacific, which has the lowest SST values. Painemal et al. (2013, their Fig. 9) showed that a remote region in the SE Pacific characterized by deeper boundary layers and warmer SSTs will break up earlier in the day than will a shallower and cooler SST region close to the coast. The disparity in the cloud fraction characteristics among regions for a given SST indicates that boundary layer depth plays a large role; other environmental factors (e.g., stability, precipitation, aerosols, and proximity to synoptic waves) are sufficiently different in expression in these regions to yield varying contributions to modulating cloudiness, however.

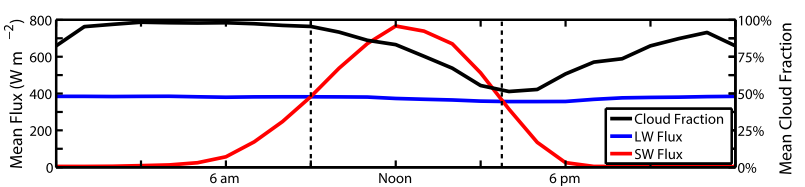

FIG. 22. Hourly mean downwelling shortwave (red line; left $y$ axis) and longwave (blue line; left $y$ axis) radiative flux measured at the surface and mean merged-IR low cloud fraction (black line; right $y$ axis) within a $1^{\circ} \times 1^{\circ}$ box centered on the Ronald $H$. Brown during the VOCALs-REx cruises. The longwave flux is primarily from the cloud deck and varies by less than $30 \mathrm{~W} \mathrm{~m}^{-2}$ across the diurnal cycle. Vertical black lines indicate the times at which the $\mathrm{SW}$ radiative flux is equal to the LW radiative flux.

To examine the relationships between radiative fluxes and cloud fraction, we can use the data collected underneath the stratocumulus cloud deck in the SE Pacific by the National Oceanic and Atmospheric Administration (NOAA) research ship Ronald H. Brown during the Variability of the American Monsoon Systems' (VAMOS) Ocean-Cloud-Atmosphere-Land Study Regional Experiment (VOCALS-REx) field campaign (de Szoeke et al. 2010; Wood et al. 2011a; Burleyson et al. 2013). VOCALS-REx took place in October and November of 2008 . We used ship data across the $20^{\circ} \mathrm{S}$ transect and confined the analysis to use only data south of $18^{\circ} \mathrm{S}$ to ensure that the sampling was in the stratocumulus region. Downwelling SW and longwave (LW) radiative fluxes were measured at the surface. We use the merged-IR low cloud masks to calculate cloud fraction in a $1^{\circ} \times 1^{\circ}$ box centered on the ship. Comparison of the diurnal cycles of cloud fraction and radiative fluxes reveals a clear relationship between net radiative flux (SW heating + LW cooling) and cloud fraction (Fig. 22). Cloud fraction starts to decrease at dawn $(\sim 0600$ LT). The rate of change of cloud fraction accelerates after $\sim 0900 \mathrm{LT}$ when SW fluxes begin to exceed LW fluxes. Rates peak near 1200 LT (Fig. 18). The cloud fraction daily minimum corresponds to the time in the afternoon $(\sim 1600 \mathrm{LT})$ at which SW fluxes start to fall below LW fluxes. By 1700 LT, although the sun is still up, cloud fraction begins to increase.

\section{Conclusions}

Patterns of cloud fraction variability across the diurnal cycle in each of the three main subtropical marine stratocumulus regions are documented using hightemporal-resolution cloud masks that are based on 30-min $4 \mathrm{~km} \times 4 \mathrm{~km}$ geosynchronous IR data for 2003-10. Our focus is on understanding the relative variability in cloud fraction over the diurnal cycle rather than in obtaining the most accurate quantitative estimate at any given time. For this purpose, our simple monospectral 
IR-based method is well suited because the inputs and quality of the retrieval do not vary diurnally. Here, we list the key results from our analysis:

1) The largest diurnal cycles and earliest time of cloud breakup occur on the edges of the cloud field where cloud fractions are generally lower (e.g., Rozendaal et al. 1995; Painemal et al. 2013, 2015). During the maximum cloudiness season in the SE Pacific and SE Atlantic, the amplitude of the diurnal cycle on the edges of the cloud deck was greater than $40 \%$, more than double the value found in the center of each cloud deck. These features provide further evidence of a positive feedback through which regions of low cloud fraction create conditions more favorable for cloud breakup.

2) The diurnal cycle of low cloud fraction within a given region unfolds in a very regular manner. Total low cloud fraction begins to decrease shortly after sunrise and continues to decrease until 1500-1600 LT. The maximum rate at which the cloud deck breaks up occurs just before or at $1200 \mathrm{LT}$ (when the SW flux is maximized), after which the cloud deck continues to break up but at a slower pace. After sunset, the rate at which cloud fraction increases in time is approximately constant.

3) The amplitude of the diurnal cycle generally increases with increasing SST (i.e., boundary layer depth) and decreasing mean cloud fraction.

4) The diurnal cycle characteristics of the Southern Hemisphere (SE Pacific and SE Atlantic) marine stratocumulus cloud decks are more similar to each other than to those in the NE Pacific. The NE Pacific stratocumulus region has weaker diurnal and seasonal variations, slower rates of cloud breakup during the day for a given cloud fraction at dawn, and a larger probability for the cloud deck to break up overnight. This result is consistent with the climatological description of Eastman and Warren (2014, their Fig. 7), which showed that stratocumuli in the two Southern Hemisphere subtropical marine stratocumulus decks have a larger-amplitude diurnal cycle when compared with behavior in the NE Pacific. These characteristics indicate that caution needs to be exercised when using NE Pacific cloud properties and modulation as close analogs for those in the SE Pacific and SE Atlantic.

The observation that lower starting cloud fractions decrease faster during the day than do cloud fractions that start near $100 \%$ is not surprising because the feedbacks are relatively well understood (e.g., Rozendaal et al. 1995). The entrainment of dry air from above the inversion erodes marine stratocumulus clouds, and the maintenance of the clouds is dependent on the supply of moisture from the ocean surface. Processes that are crucial to supplying moisture to the cloud deck-boundary layer turbulent mixing (Burleyson et al. 2013, their Fig. 2) and coupling between the surface and the cloud deck (de Szoeke et al. 2012, their Fig. 9) - are closely tied to the diurnal cycle of insolation. The diurnal variability in boundary layer turbulent mixing is driven by variations in the net cloud-top radiative flux divergence [LW cooling + SW heating; Nicholls (1984); Betts (1990); Caldwell et al. (2005); Bretherton et al. (2010)]. It takes very little solar heating to offset LW cooling and induce decoupling in the subcloud layer (Duynkerke 1989). Variations in LW cooling can come from changes in cloud fraction, cloud thickness, or cloud-top height. Daytime cloud breakup is a positive feedback because less cloud cover further weakens boundary layer turbulent mixing. The rates at which the cloud breaks up and reforms during the day highlight the importance of radiative and thermodynamic processes that are phase locked to SW fluxes (Figs. 18 and 22).

The sun acts through cloud radiative and moisture transport processes as the primary driver of cloud fraction variability in subtropical marine stratocumulus clouds. The interrelationship between SW fluxes and cloud fraction is so robust that daytime minimum cloud fraction in marine stratocumulus can be estimated from dawn (maximum) cloud fraction (Fig. 19, Table 1). The observed $20 \%-40 \%$ diurnal variation in cloudiness is much larger than variations associated with cloudaerosol-drizzle interactions (vanZanten and Stevens 2005; Comstock et al. 2005; Wood and Hartmann 2006). Our findings suggest that the difficulties in reproducing the phase and magnitude of the diurnal cycle of cloudiness in subtropical marine stratocumulus regions using current global climate models (e.g., Abel et al. 2010; Wyant et al. 2010, 2015; Medeiros et al. 2012) may be in large part related to errors in representing boundary layer height and cloud depth. Without correct cloud-top height and thickness as input, the interactions among cloud, radiation, and boundary layer turbulent mixing will yield erroneous results.

Acknowledgments. Special thanks are given to Steve Ackerman, Simon de Szoeke, Richard Frey, Jay Mace, Matthew Miller, David Mechem, Matthew Parker, Robert Pincus, Walter Robinson, and Robert Wood for their advice and technical support. Steve Platnick, Tom Arnold, and Kerry Meyer provided critical feedback on our efforts to evaluate the IR cloud fraction method. This work was funded by NOAA Climate Program Office (CPO) Climate Prediction Program for the Americas (CPPA) Grant GC09-252b, Department of 


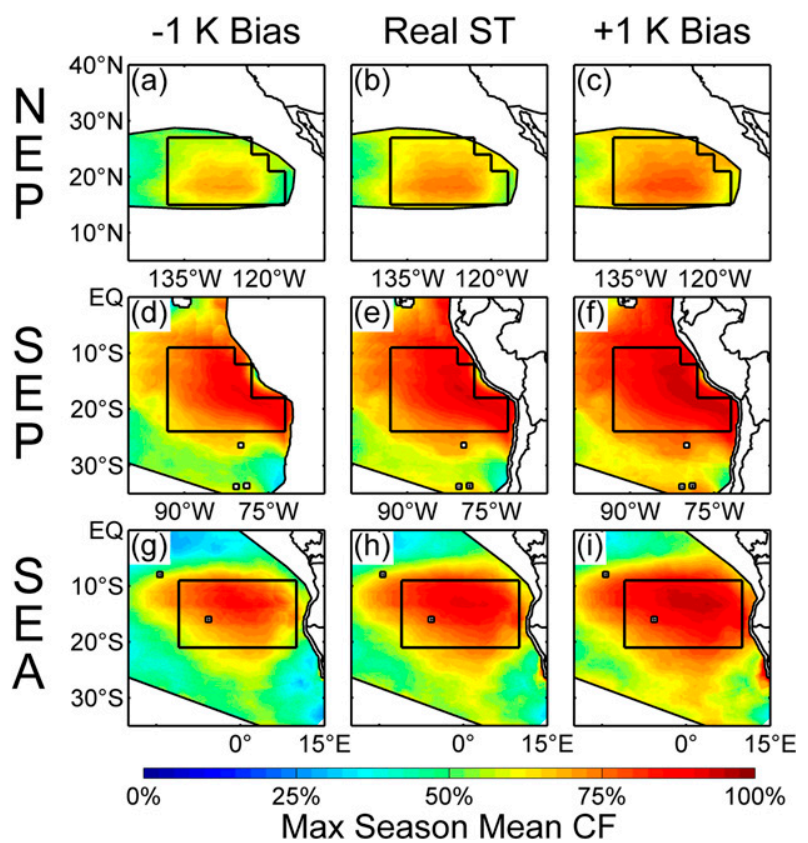

FIG. A1. Mean cloud fraction during the maximum cloudiness season found using (center) our best guess at the ST, (left) an ST that was permanently biased to be $1 \mathrm{~K}$ too cold, and (right) an ST that was permanently biased to be $1 \mathrm{~K}$ too warm. Data are shown for the (a)-(c) NE Pacific (MAM), (d)-(f) SE Pacific (SON), and (g)-(i) SE Atlantic (SON).

Energy (DOE) Atmospheric Systems Research Grant DE SC0006701, and NASA Grant NNX11AE98G. In addition, the lead author was supported in part by NASA Earth and Space Science Fellowship Grant NNX10AP43H. The Pacific Northwest National Laboratory is operated for DOE by Battelle Memorial Institute under Contract DE-AC06-76RLO 1830.

\section{APPENDIX}

\section{Sensitivity to the Selection of the Separation Temperature}

Our main findings are largely insensitive to small errors in the selection of the IR separation temperature between cloudy and cloud-free pixels. Figures A1 and A2 show the maximum season mean cloud fraction (Fig. A1) and diurnal-cycle amplitude (Fig. A2) calculated using our best-guess ST value (section 3), an ST that is permanently biased by $+1 \mathrm{~K}(\mathrm{ST}+1 \mathrm{~K})$, and an $\mathrm{ST}$ that is permanently biased by $-1 \mathrm{~K}(\mathrm{ST}-1 \mathrm{~K})$. By definition, having a permanent cold bias in the ST will lower the mean cloud fraction everywhere and having a permanent warm bias will increase the mean cloud fraction everywhere. This sensitivity test is a worst-case

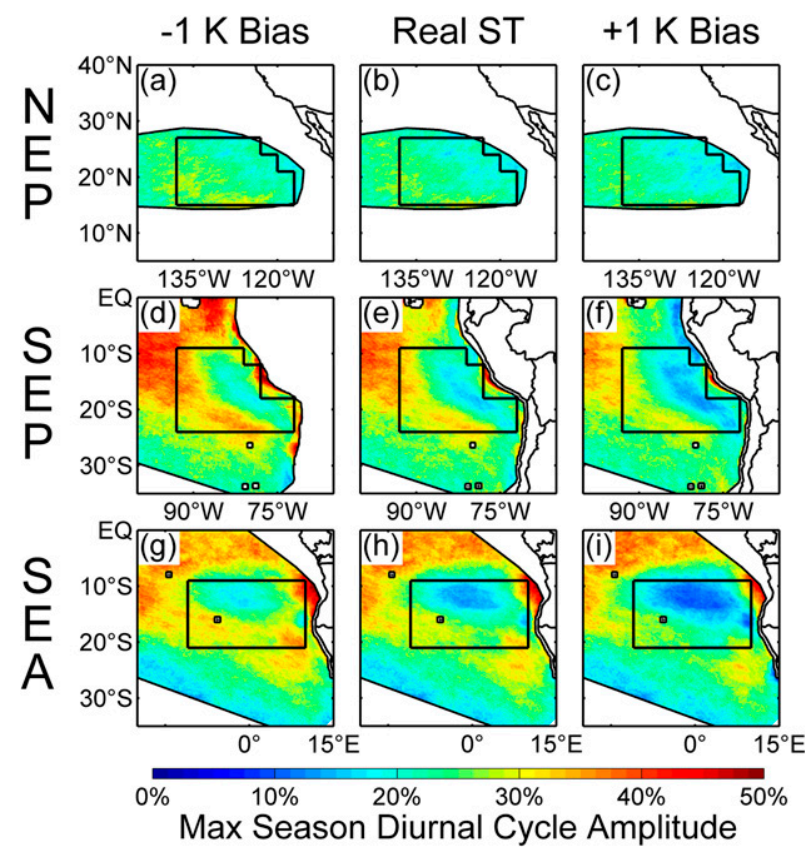

FIG. A2. As in Fig. A1, but for amplitude of the diurnal cycle of cloud fraction.

scenario because our ST values may be occasionally biased but we have no reason to believe that they would be biased consistently in one direction. Small $( \pm 1 \mathrm{~K})$ biases in the ST do not change the definitions of the maximum and minimum cloudiness season in each region (section $3 b$ ).

The overall spatial patterns of mean cloud fraction among the best-guess $\mathrm{ST}$ and with the $\pm 1 \mathrm{~K}$ perturbations are similar in each region (Fig. A1). The magnitude of the cloud fraction change within the domain was always $<10 \%$ and was most often $<5 \%$. In all three regions, a bias of $-1 \mathrm{~K}$ leads to slightly larger-amplitude diurnal cycles whereas a $+1-\mathrm{K}$ bias reduces the amplitude of the diurnal cycle, particularly in the center of each cloud deck (Fig. A2). During the maximum cloudiness seasons, nocturnal cloud fraction often reaches $100 \%$. This situation, combined with higher cloud fractions during the day, will artificially reduce the amplitude of the diurnal cycle. The magnitude of these differences varies among regions but is typically $<5 \%$. For ST $+1 \mathrm{~K}$ and ST $-1 \mathrm{~K}$, the largest-amplitude diurnal cycles still occur on the edge of the cloud deck in each region. The amplitude of the diurnal cycle is still the smallest in the NE Pacific, and the two Southern Hemisphere cloud decks are more similar to each other than to the NE Pacific. Hence, our conclusions (in particular conclusions 1,3 , and 4) are not overly sensitive to small errors in the identification of the ST in any of the three regions. 


\section{REFERENCES}

Abel, S. J., D. N. Walters, and G. Allen, 2010: Evaluation of stratocumulus cloud precipitation in the Met Office forecast model during VOCALS-REx. Atmos. Chem. Phys., 10, 10 541-10 559, doi:10.5194/acp-10-10541-2010.

Ackerman, S. A., K. I. Strabala, W. P. Menzel, R. A. Frey, C. C. Moeller, and L. E. Gumley, 1998: Discriminating clear sky from clouds with MODIS. J. Geophys. Res., 103, $32141-$ 32 157, doi:10.1029/1998JD200032.

Allen, G., and Coauthors, 2013: Gravity-wave-induced perturbations in marine stratocumulus. Quart. J. Roy. Meteor. Soc., 139, 32-45, doi:10.1002/qj.1952.

Betts, A. K., 1990: Diurnal variation of California coastal stratocumulus from two days of boundary layer soundings. Tellus, 42A, 302-304, doi:10.1034/j.1600-0870.1990.t01-1-00007.x.

Bretherton, C. S., and M. C. Wyant, 1997: Moisture transport, lower-tropospheric stability, and decoupling of cloud-topped boundary layers. J. Atmos. Sci., 54, 148-167, doi:10.1175/ 1520-0469(1997)054<0148:MTLTSA > 2.0.CO;2.

_ , R. Wood, R. C. George, D. Leon, G. Allen, and X. Zheng, 2010: Southeast Pacific stratocumulus clouds, precipitation and boundary layer structure along $20^{\circ} \mathrm{S}$ during VOCALSREx. Atmos. Chem. Phys., 10, 10 639-10 654, doi:10.5194/ acp-10-10639-2010.

Burleyson, C. D., and S. E. Yuter, 2015: Subdiurnal stratocumulus cloud fraction variability and sensitivity to precipitation. J. Climate, 28, 2968-2985, doi:10.1175/JCLI-D-14-00648.1.

- S. P. de Szoeke, S. E. Yuter, M. Wilbanks, and W. A. Brewer, 2013: Ship-based observations of the diurnal cycle of southeast Pacific marine stratocumulus clouds and precipitation. $J$. Atmos. Sci., 70, 3876-3894, doi:10.1175/JAS-D-13-01.1.

Caldwell, P., R. Wood, and C. S. Bretherton, 2005: Mixed-layer budget analysis of the diurnal cycle of entrainment in southeast Pacific stratocumulus. J. Atmos. Sci., 62, 3775-3791, doi:10.1175/JAS3561.1.

Comstock, K. K., C. S. Bretherton, and S. E. Yuter, 2005: Mesoscale variability and drizzle in southeast Pacific stratocumulus. J. Atmos. Sci., 62, 3792-3807, doi:10.1175/JAS3567.1.

de Szoeke, S. P., C. W. Fairall, D. E. Wolfe, L. Bariteau, and P. Zuidema, 2010: Surface flux observations on the southeastern tropical Pacific Ocean and attribution of SST errors in coupled ocean-atmosphere models. J. Climate, 23, 4152-4174, doi:10.1175/2010JCLI3411.1.

- , S. E. Yuter, D. Mechem, C. W. Fairall, C. D. Burleyson, and P. Zuidema, 2012: Observations of stratocumulus and their effect on the eastern Pacific surface heat budget along $20^{\circ} \mathrm{S}$. J. Climate, 25, 8542-8567, doi:10.1175/JCLI-D-11-00618.1.

Di Girolamo, L., and R. Davies, 1997: Cloud fraction errors caused by finite resolution measurements. J. Geophys. Res., 102, 1739-1756, doi:10.1029/96JD02663.

Duynkerke, P. G., 1989: The diurnal variation of a marine stratocumulus cloud: A model sensitivity study. Mon. Wea. Rev., 117, 17101725, doi:10.1175/1520-0493(1989)117<1710:TDVOAM > 2.0.CO;2.

Eastman, R., and S. G. Warren, 2014: Diurnal cycles of cumulus, cumulonimbus, stratus, stratocumulus, and fog from surface observations over land and water. J. Climate, 27, 2386-2404, doi:10.1175/JCLI-D-13-00352.1.

Frey, R. A., S. A. Ackerman, Y. Liu, K. I. Strabala, H. Zhang, J. R. Key, and X. Wang, 2008: Cloud detection with MODIS. Part I: Improvements in the MODIS cloud mask for collection 5. J. Atmos. Oceanic Technol., 25, 1057-1072, doi:10.1175/ 2008JTECHA1052.1.
Garreaud, R. D., and R. C. Muñoz, 2004: The diurnal cycle in circulation and cloudiness over the subtropical southeast $\mathrm{Pa}$ cific: A modeling study. J. Climate, 17, 1699-1710, doi:10.1175/ 1520-0442(2004)017<1699:TDCICA > 2.0.CO;2.

Hahn, C. J., and S. G. Warren, 2007: A gridded climatology of clouds over land (1971-96) and ocean (1954-97) from surface observations worldwide. Oak Ridge National Laboratory Carbon Dioxide Information Analysis Center Numeric Data Product NDP-026-E, 71 pp. [Available online at http:// www.atmos.washington.edu/ sgw/PAPERS/2007_ndp026e.pdf.]

Holz, R. E., S. A. Ackerman, F. W. Nagle, R. Frey, S. Dutcher, R. E. Keuhn, M. A. Vaughan, and B. Baum, 2008: Global Moderate Resolution Imaging Spectroradiometer (MODIS) cloud detection and height evaluation using CALIOP. J. Geophys. Res., 113, D00A19, doi:10.1029/2008JD009837.

James, D. G., 1959: Observations from aircraft of temperatures and humidities near stratocumulus clouds. Quart. J. Roy. Meteor. Soc., 85, 120-130, doi:10.1002/qj.49708536405.

Janowiak, J. E., R. J. Joyce, and Y. Yarosh, 2001: A real-time global half-hourly pixel-resolution infrared dataset and its applications. Bull. Amer. Meteor. Soc., 82, 205-217, doi:10.1175/ 1520-0477(2001)082<0205:ARTGHH >2.3.CO;2.

Jones, A. L., L. Di Girolamo, and G. Zhao, 2012: Reducing the resolution bias in cloud fraction from satellite derived clearconservation masks. J. Geophys. Res., 117, D12201, doi:10.1029/ 2011JD017195.

Joyce, R. J., and P. A. Arkin, 1997: Improved estimates of tropical and subtropical precipitation using the GOES precipitation index. J. Atmos. Oceanic Technol., 14, 997-1011, doi:10.1175/ 1520-0426(1997)014<0997:IEOTAS > 2.0.CO;2.

King, M. D., and Coauthors, 2003: Cloud and aerosol properties, precipitable water, and profiles of temperature and water vapor from MODIS. IEEE Trans. Geosci. Remote Sens., 41, 442458, doi:10.1109/TGRS.2002.808226.

Klein, S. A., and D. L. Hartmann, 1993: The seasonal cycle of low stratiform clouds. J. Climate, 6, 1587-1606, doi:10.1175/ 1520-0442(1993)006<1587:TSCOLS $>2.0$. CO;2.

, and J. R. Norris, 1995: On the relationships among lowcloud structure, sea surface temperature, and atmospheric circulations in the summertime northeast Pacific. J. Climate, 8, 1140-1155, doi:10.1175/1520-0442(1995)008<1140: OTRALC $>2.0 . \mathrm{CO} ; 2$.

Leon, D. C., Z. Wang, and D. Liu, 2008: Climatology of drizzle in marine boundary layer clouds based on 1 year of data from CloudSat and Cloud-Aerosol Lidar and Infrared Pathfinder Satellite Observations (CALIPSO). J. Geophys. Res., 113, D00A14, doi:10.1029/2008JD009835.

Lilly, D., 1968: Models of cloud-topped mixed layers under a strong inversion. Quart. J. Roy. Meteor. Soc., 94, 292-309, doi:10.1002/ qj.49709440106.

Lovejoy, S., and D. Schertzer, 1990: Fractals, raindrops and resolution dependence of rain measurements. J. Appl. Meteor., 29, 1167-1170, doi:10.1175/1520-0450(1990)029<1167: FRARDO $>2.0 . \mathrm{CO} ; 2$.

Maddux, B. C., S. A. Ackerman, and S. Platnick, 2010: Viewing geometry dependencies in MODIS cloud products. $J$. Atmos. Oceanic Technol., 27, 1519-1528, doi:10.1175/ 2010JTECHA1432.1.

Mechem, D. B., S. E. Yuter, and S. P. de Szoeke, 2012: Thermodynamic and aerosol controls in southeast Pacific stratocumulus. J. Atmos. Sci., 69, 1250-1266, doi:10.1175/JAS-D-11-0165.1.

Medeiros, B., D. L. Williamson, C. Hannay, and J. G. Olson, 2012: Southeast Pacific stratocumulus in the Community 
Atmosphere Model. J. Climate, 25, 6175-6192, doi:10.1175/ JCLI-D-11-00503.1.

Minnis, P., and E. F. Harrison, 1984: Diurnal variability of regional cloud and clear-sky radiative parameters derived from GOES data. Part I: Analysis method. J. Climate Appl. Meteor., 23, 993-1011, doi:10.1175/1520-0450(1984)023<0993: DVORCA $>2.0 . \mathrm{CO} ; 2$.

Nicholls, S., 1984: The dynamics of stratocumulus: Aircraft observations and comparisons with a mixed layer model. Quart. J. Roy. Meteor. Soc., 110, 783-820, doi:10.1002/ qj.49711046603.

Painemal, D., R. Garreaud, J. Rutllant, and P. Zuidema, 2010: Southeast Pacific stratocumulus: High-frequency variability and mesoscale structures over San Felix Island. J. Appl. Meteor. Climatol., 49, 463-477, doi:10.1175/2009JAMC2230.1.

- P. Minnis, and L. O'Neill, 2013: The diurnal cycle of cloudtop height and cloud cover over the southeastern Pacific as observed by GOES-10. J. Atmos. Sci., 70, 2393-2408, doi:10.1175/ JAS-D-12-0325.1.

, K.-M. Xu, A. Cheng, P. Minnis, and R. Palikonda, 2015: Mean structure and diurnal cycle of southeast Atlantic boundary layer clouds: Insights from satellite observations and multiscale modeling framework simulations. J. Climate, 28, 324-341, doi:10.1175/JCLI-D-14-00368.1.

Pincus, R., S. Platnick, S. A. Ackerman, R. S. Hemler, and R. J. P. Hofman, 2012: Reconciling simulated and observed views of clouds: MODIS, ISCCP, and the limits of instrument simulators. J. Climate, 25, 4699-4720, doi:10.1175/JCLI-D-11-00267.1.

Platnick, S., M. D. King, S. A. Ackerman, W. P. Menzel, B. A. Baum, and R. A. Frey, 2003: The MODIS cloud products: Algorithms and examples from Terra. IEEE Trans. Geosci. Remote Sens., 41, 459-473, doi:10.1109/TGRS.2002.808301.

Rahn, D. A., and R. D. Garreaud, 2010: Marine boundary layer over the subtropical southeast Pacific during VOCALS-RexPart I: Mean structure and diurnal cycle. Atmos. Chem. Phys., 10, 4491-4506, doi:10.5194/acp-10-4491-2010.

Reynolds, R. W., and T. M. Smith, 1994: Improved global sea surface temperature analyses using optimum interpolation. J. Climate, 7, 929-948, doi:10.1175/1520-0442(1994)007<0929: IGSSTA $>2.0 . \mathrm{CO} ; 2$.

Rossow, W. B., and R. A. Schiffer, 1991: ISCCP cloud data products. Bull. Amer. Meteor. Soc., 72, 2-20, doi:10.1175/ 1520-0477(1991)072<0002:ICDP > 2.0.CO;2.

—, and Coauthors, 1985: ISCCP cloud algorithm intercomparison. J. Climate Appl. Meteor., 24, 877-903, doi:10.1175/ 1520-0450(1985)024<0887:ICAI > 2.0.CO;2.

Rozendaal, M., C. B. Leovy, and S. A. Klein, 1995: An observational study of diurnal variations of marine stratiform cloud. J. Climate, 8,1795-1809, doi:10.1175/1520-0442(1995)008<1795: AOSODV $>2.0 . C O ; 2$.

Sandu, I., and B. Stevens, 2011: On the factors modulating the stratocumulus to cumulus transition. J. Atmos. Sci., 68, 18651881, doi:10.1175/2011JAS3614.1.
Saunders, R. W., and K. T. Kriebel, 1988: An improved method for detecting clear sky and cloudy radiances from AVHRR data. Int. J. Remote Sens., 9, 123-150, doi:10.1080/01431168808954841.

Stubenrauch, C. J., and Coauthors, 2013: Assessment of global cloud datasets from satellites: Project and database initiated by the GEWEX Radiation Panel. Bull. Amer. Meteor. Soc., 94, 1031-1049, doi:10.1175/BAMS-D-12-00117.1.

Turton, J. D., and S. Nicholls, 1987: A study of the diurnal variation of stratocumulus using a mixed layer model. Quart. J. Roy. Meteor. Soc., 113, 969-1009, doi:10.1002/qj.49711347712.

vanZanten, M. C., and B. Stevens, 2005: Observations of the structure of heavily precipitating marine stratocumulus. J. Atmos. Sci., 62, 4327-4342, doi:10.1175/JAS3611.1.

Wark, D. Q., G. Yamamoto, and J. H. Lienesch, 1962: Methods of estimating infrared flux and surface temperature from meteorological satellites. J. Atmos. Sci., 19, 369-384, doi:10.1175/ 1520-0469(1962)019<0369:MOEIFA > 2.0.CO;2.

Wielicki, B. A., and L. Parker, 1992: On the determination of cloud cover from satellite sensors: The effect of sensor spatial resolution. J. Geophys. Res., 97, 12 799-12 823, doi:10.1029/92JD01061.

Wood, R., and C. S. Bretherton, 2004: Boundary layer depth, entrainment, and decoupling in the cloud-capped subtropical and tropical marine boundary layer. J. Climate, 17, 3576-3588, doi:10.1175/1520-0442(2004)017<3576:BLDEAD>2.0.CO;2.

_ , and D. L. Hartmann, 2006: Spatial variability of liquid water path in marine low clouds: The importance of mesoscale cellular convection. J. Climate, 19, 1748-1764, doi:10.1175/JCLI3702.1.

_ , M. Köhler, R. Bennartz, and C. O'Dell, 2009: The diurnal cycle of surface divergence over the global oceans. Quart. J. Roy. Meteor. Soc., 135, 1484-1493, doi:10.1002/qj.451.

— , and Coauthors, 2011a: The VAMOS Ocean-Cloud-AtmosphereLand Study Regional Experiment (VOCALS-REx): Goals, platforms, and field operations. Atmos. Chem. Phys., 11, 627654, doi:10.5194/acp-11-627-2011.

_ C. S. Bretherton, D. Leon, A. D. Clarke, P. Zuidema, G. Allen, and H. Coe, 2011b: An aircraft case study of the spatial transition from closed to open mesoscale cellular convection over the Southeast Pacific. Atmos. Chem. Phys., 11, 23412370, doi:10.5194/acp-11-2341-2011.

Wyant, M. C., and Coauthors, 2010: The PreVOCA experiment: Modeling the lower troposphere in the Southeast Pacific. Atmos. Chem. Phys., 10, 4757-4744, doi:10.5194/acp-10-4757-2010.

_- and Coauthors, 2015: Global and regional modeling of clouds and aerosols in the marine boundary layer during VOCALS: The VOCA intercomparison. Atmos. Chem. Phys., 15, 153172, doi:10.5194/acp-15-153-2015.

Yang, Y., and L. Di Girolamo, 2008: Impacts of 3-D radiative effects on satellite cloud detection and their consequences on cloud fraction and aerosol optical depth retrievals. J. Geophys. Res., 113, D04213, doi:10.1029/2007JD009095.

Zuidema, P., D. Painemal, S. de Szoeke, and C. Fairall, 2009: Stratocumulus cloud-top height estimates and their climatic implications. J. Climate, 22, 4652-4666, doi:10.1175/2009JCLI2708.1. 